Article

\title{
Total Synthesis of Pulmonarin B and Design of Brominated Phenylacetic Acid/Tacrine Hybrids: Marine Pharmacophore Inspired Discovery of New $\mathrm{ChE}$ and $\mathrm{A} \beta$ Aggregation Inhibitors
}

\author{
Zhi-Qiang Cheng ${ }^{1}$, Jia-Li Song ${ }^{1}$, Kongkai Zhu ${ }^{1}$, Juan Zhang ${ }^{2}$, Cheng-Shi Jiang ${ }^{1, *(D)}$ \\ and Hua Zhang ${ }^{1, *}$ (iD \\ 1 School of Biological Science and Technology, University of Jinan, Jinan 250022, China; \\ czq13515312897@163.com (Z.-Q.C.); 13285419800@163.com (J.-L.S.); hkhhh.k@163.com (K.Z.) \\ 2 School of Biological Sciences, University of Brasília, Brasília 72220-275, Brazil; zjandzq@163.com \\ * Correspondence: jiangchengshi-20@163.com (C.-S.J.); bio_zhangh@ujn.edu.cn (H.Z.); \\ Tel.: +86-531-8973-6199 (H.Z.)
}

Received: 14 July 2018; Accepted: 18 August 2018; Published: 21 August 2018

\begin{abstract}
A marine natural product, pulmonarin B (1), and a series of related tacrine hybrid analogues were synthesized and evaluated as cholinesterase (ChE) inhibitors. The in vitro ChE assay results revealed that 1 showed moderate dual acetylcholinesterase (AChE)/ butyrylcholinesterase (BChE) inhibitory activity, while the hybrid $\mathbf{1 2} \mathbf{j}$ proved to be the most potent dual inhibitor among the designed derivatives, being almost as active as tacrine. Molecular modeling studies together with kinetic analysis suggested that $\mathbf{1 2} \mathbf{j}$ interacted with both the catalytic active site and peripheral anionic site of AChE. Compounds $\mathbf{1}$ and $\mathbf{1 2} \mathbf{j}$ could also inhibit self-induced and AChE-induced A $\beta$ aggregation. In addition, the cell-based assay against the human hepatoma cell line (HepG2) revealed that $\mathbf{1}$ and $\mathbf{1 2 j}$ did not show significant hepatotoxicity compared with tacrine and donepezil. Taken together, the present study confirmed that compound 1 was a potential anti-Alzheimer's disease (AD) hit, and 12j could be highlighted as a multifunctional lead compound for anti-AD drug development.
\end{abstract}

Keywords: pulmonarin B; brominated-phenylacetic acid/tacrine hybrids; acetylcholinesterase; butylcholinesterase; anti-amyloid aggregation; Alzheimer's disease

\section{Introduction}

Alzheimer's disease (AD) is a chronic neurodegenerative disorder that has become the third leading death cause behind cancer and cardiovascular diseases. AD worsens over the time with the loss of memory, decline in language skills, deficits in cognitive functions, and severe behavioral problems [1]. In 2015, about 1.9 million people died of AD [2], and in 2017, an estimated 46.8 million $\mathrm{AD}$ patients were diagnosed worldwide [3]. More seriously, the number is expected to triple by 2050 with the aging of the global population [4].

Although the cause of AD is still poorly understood nowadays, many pathogenic hypotheses have been proposed over the last three decades [5,6]. Among them, cholinergic hypothesis is undoubtedly the earliest approved, which believes that increasing the level of acetylcholine (ACh) to enhance cholinergic neurotransmission in the brain is an efficacious approach for AD treatment [7]. In the brain, ACh can be hydrolyzed by two types of cholinesterase (ChE): acetylcholinesterase (AChE) and butyrylcholinesterase (BChE) [8]. AChE is the key enzyme for the termination of neurotransmission in cholinergic pathways via its rapid hydrolysis of $\mathrm{ACh}$, almost $10^{3}$-fold more active than BChE [9]. Therefore, AChE inhibition is an effective approach for the symptomatic treatment for AD. As a result, 
four of five anti-AD drugs approved by the Food and Drug Administration (FDA) are AChE inhibitors including tacrine, donepezil, galantamine, and rivastigmine (Figure 1). These drugs are used to improve the memorial and cognitive functions of AD patients; however, none of them can stop or slow down the course of AD. Recent studies showed that the level and activity of $\mathrm{BChE}$ progressively increased in AD patients, while the activity of $\mathrm{AChE}$ declined [10]. BChE was found to serve as a backup to compensate for the function of AChE. Besides cholinergic hypothesis, amyloid hypothesis has been brought out to develop several therapeutic strategies for AD treatment. Among the factors involved in amyloid hypothesis, the formation and accumulation of beta-amyloid $(\mathrm{A} \beta)$ in the brain is considered as a primary target for developing novel anti-AD drugs, because of its ability to trigger critical intracellular signaling pathways associated with neurotoxicity, oxidative damage, and inflammation [11,12]. Due to the multifactorial nature of $\mathrm{AD}$, multi-target directed bioactive molecules are believed to simultaneously modulate different targets involved in the progression of $\mathrm{AD}$ [13]. Thus, the dual inhibition of $\mathrm{ChE}$ and $\mathrm{A} \beta$ aggregation could be a promising strategy for the treatment of AD.

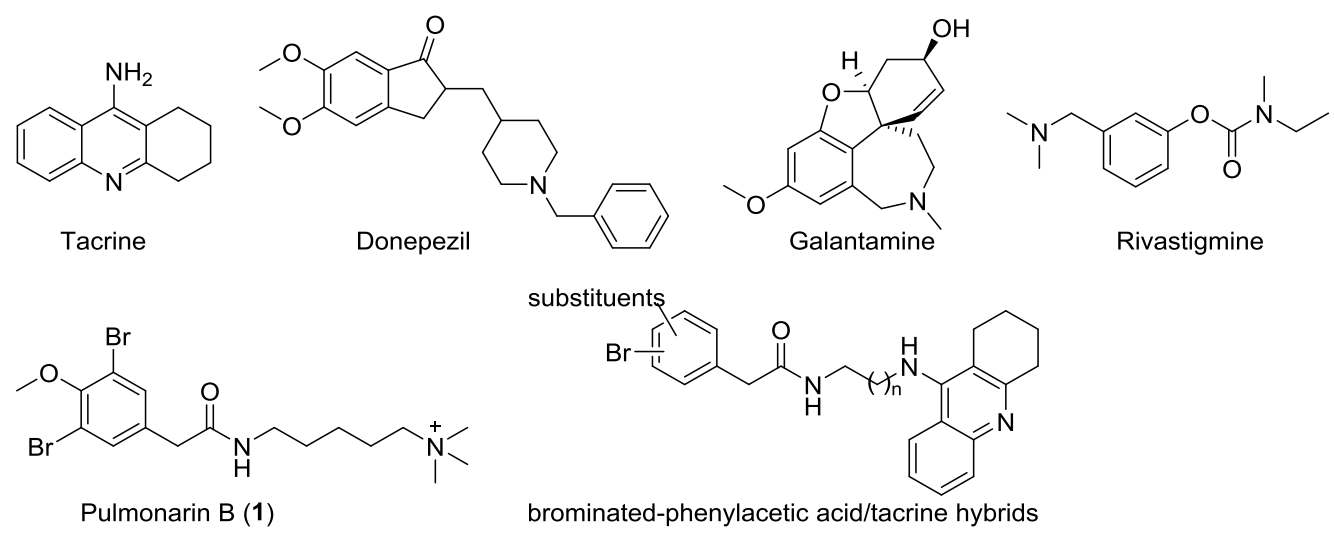

Figure 1. Structures of approved acetylcholinesterase (AChE) inhibitors, pulmonarin B (1), and brominated phenylacetic acid/tacrine hybrids.

Marine natural products (MNPs) have been proven to be an extremely important source for developing novel drugs [14,15]. As a special group of MNPs, marine halogenated metabolites possess a wide range of biological properties, such as antibacterial, antiviral, antitumor, anti-inflammatory, and neurological activities [16,17]. During our continued project for developing new ChE inhibitors [18-20], pulmonarin B (1, Figure 1), a brominated phenylacetic acid derivative isolated from the ascidian Synoicum pulmonaria by Seveson et al. [21], came to our line of sight. This dibrominated compound was reported to be an $\mathrm{AChE}$ inhibitor $\left(\mathrm{IC}_{50}=36 \mu \mathrm{M}\right)$, and was considered as a marine hit for further studies [21]. It is important to note that the discovery of marine-derived AChE inhibitors was very limited according to the latest statistics of MNPs from 1984 to 2018 [22]. Thus, we recently prepared 1 using a synthetic approach that was different from that previously reported, and retested its anti-ChE effect. The assay results revealed that 1 was a moderate dual AChE/BChE inhibitor. In addition, it showed inhibitory activity against self-induced and $A C h E-i n d u c e d ~ A \beta_{1-42}$ aggregation and non-hepatotoxicity against HepG2 cells. However, the terminal quaternary ammonium group in $\mathbf{1}$ probably makes the compound's polarity too high to pass the blood-brain barrier. To further increase the bioactive profiles of $\mathbf{1}$, molecule hybridization was applied as a powerful strategy to assemble bioactive compounds. Tacrine as a versatile pharmacophore for the design of potent $\mathrm{ChE}$ inhibitors showed excellent dual inhibition on $\mathrm{AChE} / \mathrm{BChE}$ with $\mathrm{IC}_{50}$ values at the nanomolar level [23-25]. Thus, a series of brominated phenylacetic acid/tacrine hybrids were designed by the fusion of tacrine to the terminal quaternary amine of $\mathbf{1}$. In the present study, we describe the total synthesis of $\mathbf{1}$ and its brominated phenylacetic acid/tacrine hybrids, as well as evaluate their anti-AD potential, including $\mathrm{AChE} / \mathrm{BChE}$ inhibition, molecular docking, anti-A $\beta$ aggregation, and cytotoxicity. 


\section{Results and Discussion}

\subsection{Chemistry}

Given the particularly low yield of the key intermediate 3,5-(dibromo-4-methoxyphenyl)acetic acid in the protocol reported by Seveson et al. and the high price of the starting material 5-(dimethylamino) amylamine [21], the total synthetic route of pulmonarin B (1) was redesigned and successfully achieved with the agents in hand. As illustrated in Scheme 1, methyl 2-(4-methoxyphenyl) acetate (3) was prepared from the esterification of starting material 2-(4-methoxyphenyl) acetic acid (2). Ester 3 was dibrominated with $\mathrm{NBS} / \mathrm{FeCl}_{3}$ in acetonitrile to give compound 4, which was then hydrolyzed to yield acid 5. The yield from 2 to 5 is $43 \%$, which was twofold higher than that (21\%) reported by Severson et al. Next, amide 6 was prepared by a coupling reaction of 5 with tert-butyl (5-aminopentyl)carbamate. The deprotection of the $N$-Boc group of 6 in trifluoroacetic acid directly gave amine 7 . Then, compound $\mathbf{8}$ was generated by the reductive amination of $\mathbf{7}$. Finally, $N$-methylation of $\mathbf{8}$ with $\mathrm{CH}_{3} \mathrm{I}$ enabled the full synthesis of pulmonarin B (1). The total yield of $\mathbf{1}$ was increased to $3.5 \%$, which was over twofold what was reported in the literature (1.6\%) [21]. Also, the present synthetic route afforded more pulmonarin B analogues by modifying the terminal amino group of intermediate 7 . The ${ }^{1} \mathrm{H},{ }^{13} \mathrm{C}$ NMR and MS spectrascopic data of the synthetic $\mathbf{1}$ were in agreement with those of the natural 1 [21].

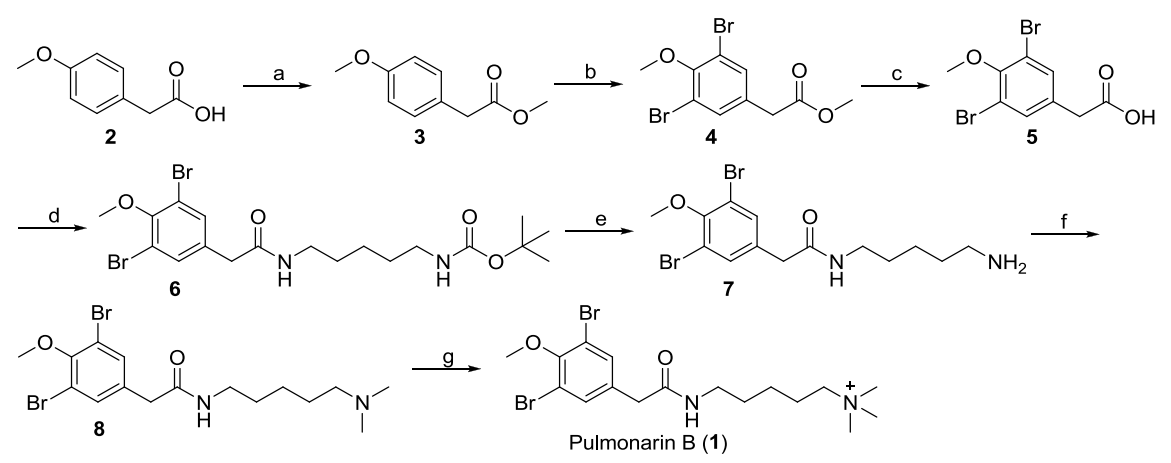

Scheme 1. Synthesis of pulmonarin B (1). (a) Thionyl chloride, $\mathrm{CH}_{3} \mathrm{OH}$, reflux; (b) N-bromosuccinimide (NBS), $\mathrm{FeCl}_{3}, \mathrm{CH}_{3} \mathrm{CN}$, room temperature (r.t.); (c) $\mathrm{CH}_{3} \mathrm{OH}, \mathrm{H}_{2} \mathrm{O}, \mathrm{NaOH}$, reflux; (d) 1-ethyl-3-(3dimethylaminopropyl)carbodiimide (EDCI), hydroxybenzotriazole (HOBT), $\mathrm{Et}_{3} \mathrm{~N}, \mathrm{CH}_{2} \mathrm{Cl}_{2}$, tert-butyl (5-aminopentyl)carbamate, r.t., $8 \mathrm{~h}$; (e) trifluoroacetic acid, $\mathrm{CH}_{2} \mathrm{Cl}_{2}$; (f) $37 \%$ formaldehyde solution, $\mathrm{NaCNBH}_{3}, \mathrm{CH}_{3} \mathrm{OH}, \mathrm{HCl}(\mathrm{aq}) ;(\mathrm{g}) \mathrm{CH}_{3} \mathrm{OH}, \mathrm{CH}_{3} \mathrm{I}, \mathrm{K}_{2} \mathrm{CO}_{3}$.

The synthetic routes for two series of compounds $\mathbf{1 0 a}-\mathbf{1 0 h}$ and $\mathbf{1 2 a - 1 2 l}$ were shown in Scheme 2. Briefly, intermediate 4 was reacted with appropriate amines to give the corresponding hybrids 10a-10h (Table 1). Similarly, the coupling reaction of $\mathbf{9 f}$ with different phenylacetic acids $\mathbf{1 1 a - 1 1 1}$ afforded the corresponding 12a-121 (Table 2).

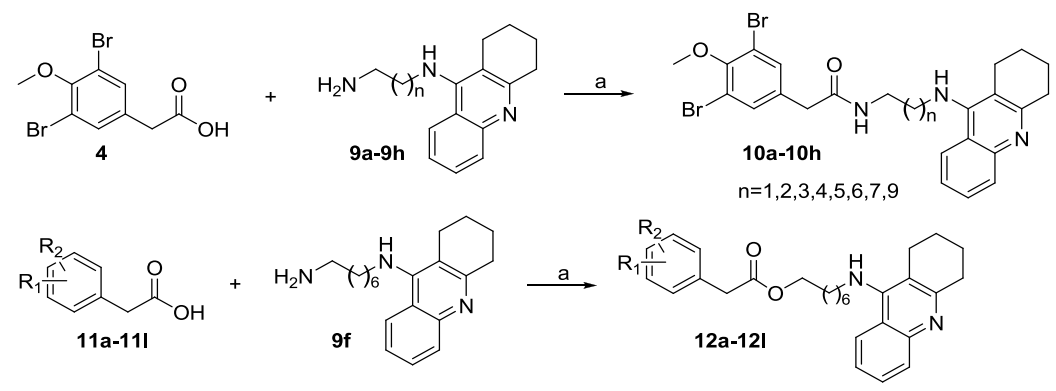

Scheme 2. Synthesis of $\mathbf{1 0 a}-\mathbf{1 0 h}$ and 12a-121. (a) EDCI, HOBT, $\mathrm{Et}_{3} \mathrm{~N}, \mathrm{CH}_{2} \mathrm{Cl}_{2}$, r.t., 8 h. 


\subsection{In Vitro Inhibition of $A C h E$ and $B C h E$, and Structure-Activity Relationship (SAR) Analysis}

At first, the in vitro $\mathrm{AChE}$ and BChE inhibitory activities of $\mathbf{1}$ were tested. From the results in Table 1 , compound 1 showed comparable AChE inhibitory activity $\left(\mathrm{IC}_{50}=37.02 \pm 2.11 \mu \mathrm{M}\right)$ to the reported value of $36 \mu \mathrm{M}$ [21]. In addition, it was also found to be a BChE inhibitor with an $\mathrm{IC}_{50}$ value of $30.70 \pm 1.44 \mu \mathrm{M}$. However, the $\mathrm{ChE}$ inhibitory activity of $\mathbf{1}$ was much weaker than that of the positive control tacrine ( $\left.\mathrm{AChE}, \mathrm{IC}_{50}=0.159 \pm 0.007 \mu \mathrm{M} ; \mathrm{BChE}, \mathrm{IC}_{50}=0.046 \pm 0.002 \mu \mathrm{M}\right)$. Aiming to improve the activity of 1, brominated phenylacetic acid/tacrine hybrids 10a-10h were prepared based on molecule hybridization. Compared with 1, all of these hybrids showed more potent ChE inhibitory activity, and clearly this improvement could be attributed to the introduction of tacrine moiety. In both enzyme bioassays, compound $10 \mathrm{f}$ with 7-carbon aliphatic spacer in the linker showed the best activity (AChE, $\left.\mathrm{IC}_{50}=0.314 \pm 0.010 \mu \mathrm{M} ; \mathrm{BChE}, \mathrm{IC}_{50}=0.053 \pm 0.007 \mu \mathrm{M}\right)$. The preliminary SAR study indicated that the $\mathrm{ChE}$ inhibitory activities of these compounds increased with the elongation of the diamine linker (from 10a to 10f) and then decreased (from 10f to 10h), and the 7-carbon diamino linkage seemed to be the optimal distance between the brominated phenylacetyl and 1,2,3,4-tetrahydroacridine moieties.

Table 1. In vitro inhibition of $\mathrm{AChE}$ and butyrylcholinesterase $(\mathrm{BChE})$ presented as $\mathrm{IC}_{50}(\mu \mathrm{M})^{1}$.

\begin{tabular}{cccc}
\hline & & \\
& & \\
\end{tabular}

Next, the substituent effect of benzene was investigated, and compound $\mathbf{1 0 f}$ was selected as a model compound for further structural modification. Consequently, 12 analogues (12a-12l) were prepared, and their bioassay results were shown in Table 1 . Among these analogues, compound $\mathbf{1 2} \mathbf{j}$ showed the best ChE inhibitory activity ( $\mathrm{AChE}, \mathrm{IC}_{50}=0.182 \pm 0.006 \mu \mathrm{M} ; \mathrm{BChE}, \mathrm{IC}_{50}=0.064 \pm 0.006 \mu \mathrm{M}$ ), which was almost equal to that of tacrine. From the bioassay results, it was clear that different substituents had obvious impact on the AChE and BChE inhibitory activities. For example, compound $\mathbf{1 2} \mathbf{j}$ with $5-\mathrm{Br}$ and 2-F showed increased inhibitory activity toward AChE by fourfold compared with 12a, and toward $\mathrm{BChE}$ by fourfold over 12f. Compounds $\mathbf{1 2 b}$ and $\mathbf{1 2 l}$ without $\mathrm{Br}$ substitution showed low anti-ChE activity in comparison with $\mathbf{1 2} \mathbf{j}$. 


\subsection{Kinetic Study of AChE and BChE Inhibition}

Herein, compound $\mathbf{1 2} \mathbf{j}$ was selected as a representative prototype for kinetic assay to obtain information on the mode of action and binding site of this series of analogues. The mechanisms of $\mathrm{AChE}$ and $\mathrm{BChE}$ inhibitions were analyzed by recording substrate concentration-enzyme velocity curves in the presence of different concentrations of $\mathbf{1 2} \mathbf{j}$.

Graphical analyses revealed both increasing slopes (decreasing $V_{\max }$ ) and increasing intercepts $\left(K_{\max }\right)$ at rising concentrations of $\mathbf{1 2} \mathbf{j}$ (Figures $2 \mathrm{~A}$ and $3 \mathrm{~A}$ ). The equilibrium constant for binding with the free enzyme $\left(K_{\mathrm{i}}\right)$ was obtained from the slope against inhibitor concentration [26]. The estimated $K_{\mathrm{i}}$ value of $\mathbf{1 2} \mathbf{j}$ was $97.50 \mathrm{nM}$ for AChE (Figure 2B), and that for BChE was $9.91 \mathrm{nM}$ (Figure 3B). These patterns revealed compound $\mathbf{1 2} \mathbf{j}$ as a linear mixed-type $\mathrm{ChE}$ inhibitor, indicating that $\mathbf{1 2} \mathbf{j}$ may not only bind to the catalytic active site (CAS), but also interact with the peripheral anionic site (PAS) of both enzymes.
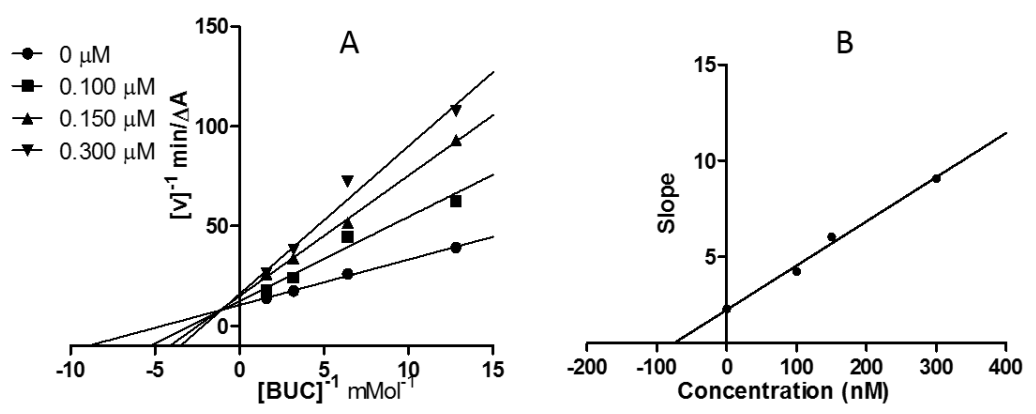

Figure 2. Kinetic assay on AChE inhibition displayed by $\mathbf{1 2 j}$. (A) Lineweaver-Burk reciprocal plots of initial velocity and increasing substrate concentrations $(0.078-0.625 \mathrm{mM})$; (B) Secondary plot of slopes versus $\mathbf{1 2} \mathbf{j}$ concentrations.
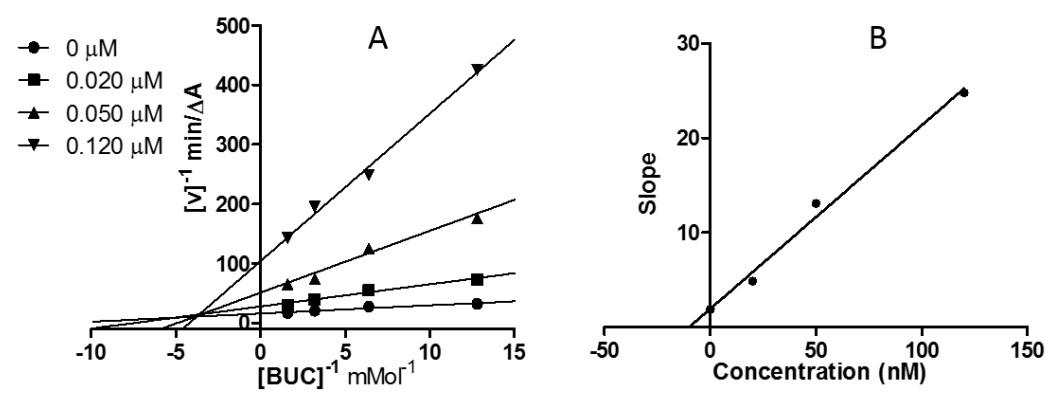

Figure 3. Kinetic assay on BChE inhibition displayed by 12j. (A) Lineweaver-Burk reciprocal plots of initial velocity and increasing substrate concentrations $(0.078-0.625 \mathrm{mM})$; (B) Secondary plot of slopes versus $\mathbf{1 2} \mathbf{j}$ concentrations.

\subsection{Docking Study}

As compound 12j showed the best inhibition toward AChE, it was selected for docking simulation. First, the ligand alkylene-linked bis-tacrine that was derived from the original X-ray structure of AChE (PDB ID: 5EI5) was redocked to the protein to validate the molecular modeling methodology, as shown in Figure S1 (Supporting Information). The docking result could well reproduce the crystal structure, which indicated that the method was suitable for a docking study of AChE. Since the redocking of the ligand tacrine that originated from BChE (PDB ID: 4BDS) to its protein could not well reproduce the crystal structure, the binding mode of $\mathbf{1 2} \mathbf{j}$ with $\mathrm{BChE}$ was not discussed in this study. As shown in Figure $4 \mathbf{1 2} \mathbf{j}$ was obviously able to bind to the active pocket of AChE. Here, AChE (PDB: 5EI5) [27] was used in the docking analysis because of its high resolution. The docking score for $\mathbf{1 2 j}$ / AChE was -17.50 . The tacrine moiety of $\mathbf{1 2} \mathbf{j}$ could be spatially located in CAS (Figure $4 \mathrm{~A}$ ) and showed stacking 
interactions with Trp84 and Phe330 (Figure 4B). Furthermore, the protonated nitrogen atom in the tacrine ring underwent cation interaction with residues Phe330 and Trp84, and also formed an H-bond with the key residue His440. The brominated benzene moiety was oriented in the PAS by forming stacking interactions with Try70, Try121, and Trp279. The H atom of the amide group serves as an $\mathrm{H}$-bond donor for interacting with Tyr121. In addition, hydrophobic interactions between $\mathbf{1 2} \mathbf{j}$ and key residues also contributed to the affinity of $\mathbf{1 2} \mathbf{j}$ to $\mathrm{AChE}$.

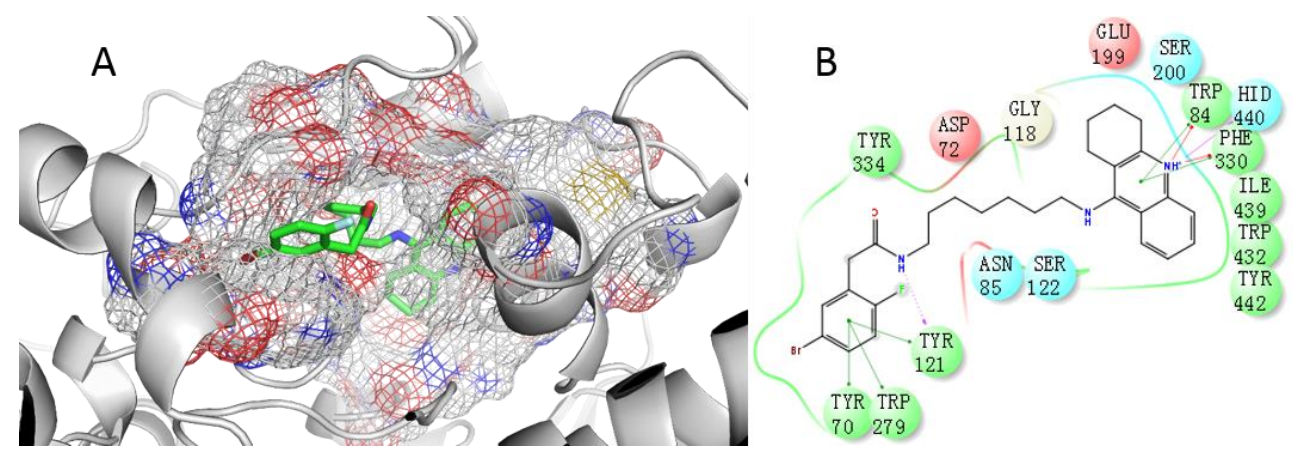

Figure 4. (A) The proposed orientation of $\mathbf{1 2} \mathbf{j}$ (carbon in green) in the active pocket of AChE;

(B) The interactions of $\mathbf{1 2} \mathbf{j}$ with key amino acid residues in the active site of AChE.

\subsection{Inhibition of Self-Induced and AChE-Induced A Aggregation}

Studies showed that $\mathrm{ChE}$ inhibitors not only increased the levels of $\mathrm{ACh}$ in the brain, they also reduced and prevented the formation of $A \beta$ aggregation [28]. Compounds $\mathbf{1}$ and $\mathbf{1 2} \mathbf{j}$ were assessed for their ability to inhibit self-induced and AChE-induced $A \beta_{1-42}$ aggregation using the thioflavin $\mathrm{T}$ (ThT) fluorescence method. Tacrine and donepezil were used as positive reference compounds, and galantamine was included as a negative control. The results are shown in Table 2. The inhibitions of compound $\mathbf{1}$ and $\mathbf{1 2} \mathbf{j}$ at $10 \mu \mathrm{M}$ against self-induced $\mathrm{A} \beta_{1-42}$ aggregation were $29.78 \pm 1.45 \%$ and $32.37 \pm 0.62 \%$, respectively, which were higher than that of donepezil $(17.95 \pm 0.77 \%)$. In addition, compounds $\mathbf{1}$ and $\mathbf{1 2} \mathbf{j}$ also exhibited a significant inhibitory effect on AChE-induced A $\beta$ aggregation, with inhibition ratios of $27.60 \pm 1.96 \%$ and $47.73 \pm 4.35 \%$, respectively. As for galantamine, no significant inhibition was observed in self-induced and AChE-induced $A \beta_{1-42}$ aggregation assay.

Table 2. Inhibition of self-induced and AChE-induced A $\beta$ aggregation by compounds $\mathbf{1}$ and $\mathbf{1 2} \mathbf{j}$ in comparison with tacrine, donepezil, and galantamine.

\begin{tabular}{ccc}
\hline \multirow{2}{*}{ Compounds } & \multicolumn{2}{c}{ Inhibition of $\mathbf{A} \boldsymbol{\beta}$ Aggregation (\%) } \\
\cline { 2 - 3 } & Self-Induced $^{\mathbf{1}}$ & AChE-Induced $^{\mathbf{2}}$ \\
\hline $\mathbf{1}$ & $29.78 \pm 1.45$ & $27.60 \pm 1.96$ \\
$\mathbf{1 2} \mathbf{j}$ & $32.37 \pm 0.62$ & $47.73 \pm 4.35$ \\
Tacrine & $\mathrm{NT}^{3}$ & $21.84 \pm 1.60$ \\
Donepezil & $17.95 \pm 0.77$ & $22.42 \pm 2.56$ \\
Galantamine & $1.25 \pm 0.46$ & $3.58 \pm 1.42$ \\
\hline
\end{tabular}

${ }^{1}$ Inhibition of self-induced $\mathrm{A} \beta_{1-42}$ aggregation $(2.5 \mu \mathrm{M})$ produced by the tested compounds at $10 \mu \mathrm{M}$ concentration. Values are expressed as the mean \pm SD of three separate experiments. ${ }^{2}$ Co-aggregation inhibition of $\mathrm{A} \beta_{1-42}$ aggregation $(2.5 \mu \mathrm{M})$ and $\mathrm{AChE}(0.2 \mathrm{U} / \mathrm{mL})$ by the tested compounds at $8 \mu \mathrm{M}$ concentration. Values are expressed as the mean $\pm \mathrm{SD}$ of three separate experiments. ${ }^{3}$ Not tested.

\subsection{In Vitro Cytotoxicity toward HepG2 Cells}

The main reason for the withdrawal of tacrine from the market is its hepatotoxicity. Thus, to verify the hepatotoxicity of $\mathbf{1}$ and $\mathbf{1 2} \mathbf{j}$, a 3-(4,5-dimethylthiazol-2-yl)-2,5-diphenyltetrazolium bromide (MTT) assay $[29,30]$ on the human hepatoma cell line (HepG2) was carried out. Tacrine and donepezil were used as control drugs, and the $\mathrm{IC}_{50}$ values of all of the tested compounds toward HepG2 cells were 
summarized in Table 3. The results indicated that compounds $\mathbf{1}$ and $\mathbf{1 2} \mathbf{j}$ did not show significant cytotoxicity against HepG2 cell (cell viability $>50 \%$ up to $80 \mu \mathrm{M}$ ) compared with tacrine and donepezil.

Table 3. Results of in vitro cytotoxicity toward human hepatoma cell line (HepG2) cells.

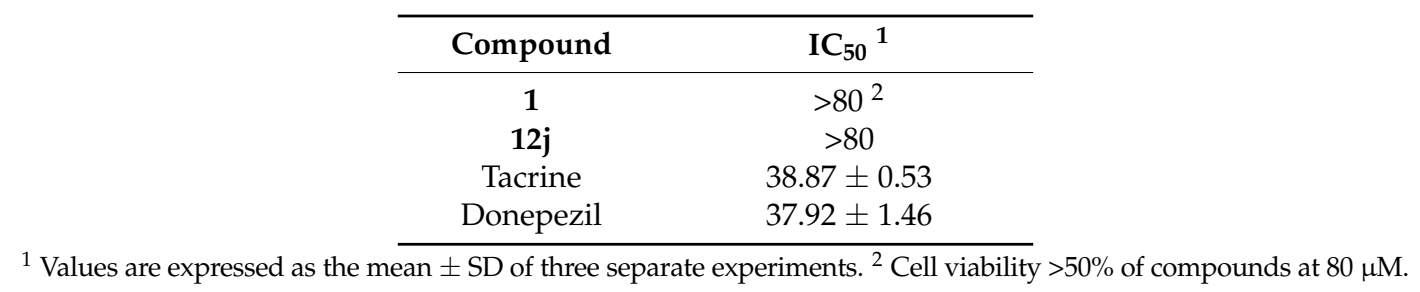

\section{Materials and Methods}

\subsection{General Information}

Melting points were measured by a Melting Point YRY-3 apparatus (Tianjin Precision Apparatus Factory, Tianjin, China). Commercially available reagents were used without further purification. Organic solvents were evaporated with reduced pressure using Büchi R-100 evaporators. Reactions were monitored by thin-layer chromatography (TLC) using Yantai JingYou (Yantai, China) GF254 silica gel plates. Silica gel column chromatography was performed on an Isolera One system (Biotage, Uppsala, Sweden) with and silica gel (200-300 mesh) from Qingdao Hailang Inc. (Qingdao, China). NMR spectra were measured on a BrukerAvance III 600 spectrometer (Bruker, Fällanden, Switzerland). Chemical shifts were expressed in $\delta(\mathrm{ppm})$ and coupling constants $(J)$ in $\mathrm{Hz}$, with residual solvent signals as internal standards $\left(\mathrm{CDCl}_{3}, \delta_{\mathrm{H}} 7.26 \mathrm{ppm}\right.$ and $\delta_{\mathrm{C}} 77.0 \mathrm{ppm} ; \mathrm{DMSO}-d_{6}, \delta_{\mathrm{H}} 2.50 \mathrm{ppm}$ and $\delta_{\mathrm{C}}$ $39.5 \mathrm{ppm}$ ). Electron spray ionization (ESI)-MS analyses were performed on an Agilent 1260-6460 Triple Quard LC-MS instrument and HR-ESI-MS data were acquired on an Agilent Q-TOF 6520 spectrometer (Agilent, Waldbronn, Germany).

\subsection{Chemistry}

Methyl 2-(4-methoxyphenyl) acetate (3). Thionyl chloride ( $2.5 \mathrm{mg}, 0.021 \mathrm{mmol}, 0.003$ equiv.) was added to a solution of 2-(4-methoxyphenyl) acetic acid (1156 mg, $7 \mathrm{mmol}, 1$ equiv.) in methanol (5 mL) at $0{ }^{\circ} \mathrm{C}$. Then, the reaction solution was refluxed for $4 \mathrm{~h}$. The solution was concentrated under reduced pressure to give 3 , which was used in the next step without further purification. Colorless oil. Yield: $1215 \mathrm{mg}, 96.4 \% .{ }^{1} \mathrm{H}$ NMR $\left(600 \mathrm{MHz}, \mathrm{CDCl}_{3}\right) \delta 7.20(\mathrm{~d}, J=8.7 \mathrm{~Hz}, 2 \mathrm{H}), 6.86(\mathrm{~d}, J=8.7 \mathrm{~Hz}, 2 \mathrm{H}), 3.79$ $(\mathrm{s}, 3 \mathrm{H}), 3.68(\mathrm{~s}, 3 \mathrm{H}), 3.57(\mathrm{~s}, 2 \mathrm{H}) .{ }^{13} \mathrm{C}$ NMR $\left(150 \mathrm{MHz}, \mathrm{CDCl}_{3}\right) \delta 172.5,158.8,130.4,126.2,114.1,55.4$, 52.1, 40.4. ESI-MS $m / z 203.0[\mathrm{M}+\mathrm{Na}]^{+}$.

2-(3,5-Dibromo-4-methoxyphenyl)acetate (4). Ferric chloride (1097 mg, $6.75 \mathrm{mmol}, 1$ equiv.) and NBS (2403 mg, $13.5 \mathrm{mmol}, 2$ equiv.) were added to a solution of 3 (1215 mg, $6.75 \mathrm{mmol}, 1$ equiv.) in $\mathrm{CH}_{3} \mathrm{CN}$ at $0{ }^{\circ} \mathrm{C}$. The mixture was stirred for $5 \mathrm{~h}$ at room temperature. After purification by flash chromatography, product 4 was obtained in moderate yield. Colorless oil. Yield: $1540 \mathrm{mg}, 67.5 \%$. ${ }^{1} \mathrm{H} \mathrm{NMR}\left(600 \mathrm{MHz}, \mathrm{CDCl}_{3}\right) \delta 7.43(\mathrm{~s}, 2 \mathrm{H}), 3.87(\mathrm{~s}, 3 \mathrm{H}), 3.71(\mathrm{~s}, 3 \mathrm{H}), 3.53(\mathrm{~s}, 2 \mathrm{H}) .{ }^{13} \mathrm{C}$ NMR $(150 \mathrm{MHz}$, $\left.\mathrm{CDCl}_{3}\right) \delta 171.1,153.5,133.6,132.5,118.2,60.8,52.5,39.7$. ESI-MS $m / z 335.9[\mathrm{M}+\mathrm{H}]^{+}$.

2-(3,5-Dibromo-4-methoxyphenyl)acetic acid (5). A solution of 4 (1540 mg, $4.5 \mathrm{mmol}, 1$ equiv.) and $\mathrm{NaOH}\left(540 \mathrm{mg}, 13.5 \mathrm{mmol}, 3\right.$ equiv.) in $\mathrm{CH}_{3} \mathrm{OH}-\mathrm{H}_{2} \mathrm{O}(v: v=9: 1,10 \mathrm{~mL})$ was refluxed for $24 \mathrm{~h}$. Then, the reaction mixture was acidified with $1 \mathrm{M} \mathrm{HCl}$ and filtered. The obtained filter was washed three times with water to give compound 5, which was used for the next step without further purification. White solid. Yield: $956 \mathrm{mg}, 66.2 \%$. Mp. $125.2-126.6^{\circ} \mathrm{C} .{ }^{1} \mathrm{H}$ NMR $\left(600 \mathrm{MHz}, \mathrm{DMSO}-d_{6}\right) \delta 12.51(\mathrm{~s}, 1 \mathrm{H}$, $\mathrm{COOH}), 7.57(\mathrm{~s}, 2 \mathrm{H}), 3.78(\mathrm{~s}, 3 \mathrm{H}), 3.60(\mathrm{~s}, 2 \mathrm{H}) .{ }^{13} \mathrm{C}$ NMR $\left(150 \mathrm{MHz}, \mathrm{DMSO}-d_{6}\right) \delta 172.1,152.0,134.6$, $133.9,116.9,60.4,38.6$. ESI-MS $m / z 322.8[\mathrm{M}+\mathrm{H}]^{+}$. 
Tert-butyl 5-(2-(3,5-dibromo-4-methoxyphenyl)acetamido)pentylcarbamate (6). A 10-mL flask was charged with 5 (162 mg, 0.5 mmol, 1 equiv.), Et ${ }_{3} \mathrm{~N}$ (151.5 mg, 4.5 mmol, 3 equiv.), HOBT ( $33.7 \mathrm{mg}, 0.25 \mathrm{mmol}$, 0.5 equiv.), 1-ethyl-3-(3-dimethylaminopropyl)carbodiimide (EDCI) (143.2 mg, $0.75 \mathrm{mmol}, 1.5$ equiv.) and tert-butyl (5-aminopentyl)carbamate ( $101 \mathrm{mg}, 0.5 \mathrm{mmol}, 1.0$ equiv.) under nitrogen atmosphere. After dissolution in $5 \mathrm{~mL}$ of anhydrous dichloromethane (DCM), the mixture was stirred at room temperature for $8 \mathrm{~h}$. The organic phase was washed three times with water and dried over anhydrous $\mathrm{MgSO}_{4}$. The residue was purified by flash chromatography (petroleum ether:EtOAc $=1: 1$ ) to give product 6. Colorless oil. Yield: $133 \mathrm{mg}, 52.3 \% .{ }^{1} \mathrm{H}$ NMR $\left(600 \mathrm{MHz}, \mathrm{CDCl}_{3}\right) \delta 7.43(\mathrm{~s}, 2 \mathrm{H}), 5.80$ (brs, $1 \mathrm{H}, \mathrm{NH}), 3.86(\mathrm{~s}, 3 \mathrm{H}), 3.43(\mathrm{~s}, 2 \mathrm{H}), 3.24-3.21(\mathrm{~m}, 2 \mathrm{H}), 3.12-3.08(\mathrm{~m}, 2 \mathrm{H}), 1.52-1.47(\mathrm{~m}, 4 \mathrm{H}), 1.43(\mathrm{~s}, 9 \mathrm{H})$, 1.33-1.29 (m, 2H). ${ }^{13} \mathrm{C} \mathrm{NMR}\left(150 \mathrm{MHz}, \mathrm{CDCl}_{3}\right) \delta 169.7,156.3,153.4,133.9,133.5,118.4,79.3,60.7,42.2$, $40.3,39.8,29.9,29.1,28.6,24.0$. ESI-MS $m / z 540.9\left[\mathrm{M}+\mathrm{Cl}^{-}\right.$.

Tert-butyl 5-(2-(3,5-dibromo-4-methoxyphenyl)acetamido)pentylcarbamate (8). Compound 6 (127 mg, $0.25 \mathrm{mmol}, 1$ equiv.) was treated with trifluoroacetic acid $(285 \mathrm{mg}, 2.5 \mathrm{mmol}, 10$ equiv.) in $5 \mathrm{~mL}$ $\mathrm{DCM}$ at $0{ }^{\circ} \mathrm{C}$ to produce 7 , which was used in the next reaction without further purification. A solution of 7, 37\% formaldehyde solution ( $16.5 \mathrm{mg}, 0.55 \mathrm{mmol}, 2.5$ equiv.), $\mathrm{NaCNBH}_{3}$ (41.4 mg, $0.66 \mathrm{mmol}$, 3 equiv.) and $12 \mathrm{M} \mathrm{HCl}(\mathrm{aq})\left(0.055 \mathrm{~mL}, 0.66 \mathrm{mmol}, 3\right.$ equiv.) was stirred in $\mathrm{CH}_{3} \mathrm{OH}(5 \mathrm{~mL})$ for $12 \mathrm{~h}$. Then, the solution was concentrated, and the residue was purified by flash chromatography $\left(\mathrm{CH}_{2} \mathrm{Cl}_{2}: \mathrm{CH}_{3} \mathrm{OH}\right.$ = 9:1) to give product 8. Yellow oil. Yield: $90.3 \mathrm{mg}, 94.2 \% .{ }^{1} \mathrm{H}$ NMR $\left(600 \mathrm{MHz}, \mathrm{CDCl}_{3}\right) \delta 7.42(\mathrm{~s}, 2 \mathrm{H})$, $3.86(\mathrm{~s}, 3 \mathrm{H}), 3.42(\mathrm{~s}, 2 \mathrm{H}), 3.25-3.21(\mathrm{~m}, 2 \mathrm{H}), 2.28-2.25(\mathrm{~m}, 2 \mathrm{H}), 2.22(\mathrm{~s}, 6 \mathrm{H}), 1.51-1.45(\mathrm{~m}, 4 \mathrm{H}), 1.33-1.28$ (m, 2H). ${ }^{13} \mathrm{C}$ NMR $\left(150 \mathrm{MHz}, \mathrm{CDCl}_{3}\right) \delta 169.7,153.4,133.9,133.5,118.4,60.8,59.4,45.4,42.3,39.9,29.2$, 27.1, 24.6. ESI-MS $m / z 435.0[\mathrm{M}+\mathrm{H}]^{+}$.

Pulmonarin B (1). An amount of 8 ( $90 \mathrm{mg}, 0.2 \mathrm{mmol}, 1$ equiv.) was dissolved in $5 \mathrm{~mL}$ of $\mathrm{CH}_{3} \mathrm{OH}$, and then $\mathrm{K}_{2} \mathrm{CO}_{3}$ (57 mg, $0.4 \mathrm{mmol}, 2$ equiv.) was added. The resulting mixture was stirred at room temperature for $15 \mathrm{~min}$ before methyl iodide ( $31 \mathrm{mg}, 0.22 \mathrm{mmol}, 1.1$ equiv.) was added. The reaction was stirred overnight, and then all of the volatiles were evaporated. A final purification of $10 \mathrm{mg}$ of crude solid material gave purified 1 by using semipreparative reversed-phase $\mathrm{HPLC}\left(\mathrm{CH}_{3} \mathrm{OH} / \mathrm{H}_{2} \mathrm{O} / \mathrm{CH}_{3} \mathrm{COOH}\right.$ $\left.=1: 1: 0.4 \times 10^{-4}\right)$. White solid. Yield: $1.5 \mathrm{mg}, 16.6 \% .{ }^{1} \mathrm{H}$ NMR $\left(600 \mathrm{MHz}\right.$, DMSO- $\left.d_{6}\right) \delta 8.49(\mathrm{t}, J=5.9 \mathrm{~Hz}$, $1 \mathrm{H}, \mathrm{NH}), 7.56(\mathrm{~s}, 2 \mathrm{H}), 3.77(\mathrm{~s}, 3 \mathrm{H}), 3.43(\mathrm{~s}, 2 \mathrm{H}), 3.28-3.24(\mathrm{~m}, 2 \mathrm{H}), 3.05(\mathrm{~s}, 9 \mathrm{H}), 3.05-3.03(\mathrm{~m}, 2 \mathrm{H})$, $1.69-1.66(\mathrm{~m}, 2 \mathrm{H}), 1.48-1.42(\mathrm{~m}, 2 \mathrm{H}), 1.28-1.24(\mathrm{~m}, 2 \mathrm{H}) .{ }^{13} \mathrm{C}$ NMR (150 MHz, DMSO-d 6 ) $\delta 169.3,151.9$, 136.2, 133.3, 116.9, 65.2, 65.2, 60.4, 52.1, 40.5, 38.3, 28.4, 23.2, 21.7. ESI-MS $m / z$ 449.0 [M] ${ }^{+}$. HR-ESIMS: $[\mathrm{M}]^{+}$calculated for $\mathrm{C}_{17} \mathrm{H}_{27} \mathrm{Br}_{2} \mathrm{~N}_{2} \mathrm{O}_{2}{ }^{+} 449.0434$, found 449.0439.

General Procedures for the Synthesis of 10a-10h and 12a-121

For the synthesis of 10a-10h, the mixtures of 2-(3,5-dibromo-4-methoxyphenyl)acetic acid (4, $80 \mathrm{mg}, 0.25 \mathrm{mmol}, 1$ equiv.), hydroxybenzotriazole (HOBT) (19 mg, $0.125 \mathrm{mmol}, 0.5$ equiv.), EDCI ( $58 \mathrm{mg}, 0.375 \mathrm{mmol}, 1.5$ equiv.), triethylamine $(75 \mathrm{mg}, 0.75 \mathrm{mmol}, 3$ equiv.), and corresponding amines 9a-9h ( $0.25 \mathrm{mmol}, 1$ equiv.) in $5 \mathrm{~mL}$ of $\mathrm{CH}_{2} \mathrm{Cl}_{2}$ were stirred at room temperature overnight. For the synthesis of 12a-121, the mixtures of corresponding phenylacetic acids 11a-111 ( $0.26 \mathrm{mmol}, 1$ equiv.), HOBT ( $20 \mathrm{mg}, 0.13 \mathrm{mmol}, 0.5$ equiv.), EDCI ( $60 \mathrm{mg}, 0.39 \mathrm{mmol}, 1.5$ equiv.), triethylamine (79 mg, $0.78 \mathrm{mmol}, 3$ equiv.), and $N^{1}$-(1,2,3,4-tetrahydroacridin-9-yl)heptane-1,7-diamine ( $80 \mathrm{mg}, 0.26 \mathrm{mmol}$, 1 equiv.) in $5 \mathrm{~mL}$ of $\mathrm{CH}_{2} \mathrm{Cl}_{2}$ were stirred at room temperature overnight. The above solutions were evaporated, and the residues were purified by flash chromatography using $\mathrm{CH}_{2} \mathrm{Cl}_{2}: \mathrm{MeOH}=10: 1$ as an eluent to give the target compounds 10a-10h and 12a-121.

2-(3,5-Dibromo-4-methoxyphenyl)-N-(2-((1,2,3,4-tetrahydroacridin-9-yl)amino)ethyl)acetamide (10a). White solid. Yield: $57.8 \mathrm{mg}, 42.3 \%$. Mp. $97.4-100.0{ }^{\circ} \mathrm{C} .{ }^{1} \mathrm{H}$ NMR $\left(600 \mathrm{MHz}, \mathrm{CDCl}_{3}\right) \delta 9.11$ (brs, $\left.1 \mathrm{H}, \mathrm{NH}\right), 8.19$ $(\mathrm{d}, J=8.4 \mathrm{~Hz}, 1 \mathrm{H}), 8.12(\mathrm{~d}, J=8.7 \mathrm{~Hz}, 1 \mathrm{H}), 7.52(\mathrm{~s}, 2 \mathrm{H}), 7.45(\mathrm{dd}, J=8.7,7.5 \mathrm{~Hz}, 1 \mathrm{H}), 7.40(\mathrm{brs}, 1 \mathrm{H}$, $\mathrm{NH}), 7.26(\mathrm{dd}, J=8.4,7.5 \mathrm{~Hz}, 1 \mathrm{H}), 4.11-4.06(\mathrm{~m}, 2 \mathrm{H}), 3.78(\mathrm{~s}, 3 \mathrm{H}), 3.76-3.71(\mathrm{~m}, 2 \mathrm{H}), 3.66(\mathrm{~s}, 2 \mathrm{H}), 3.11$ $(\mathrm{t}, J=6.2 \mathrm{~Hz}, 2 \mathrm{H}), 2.48(\mathrm{t}, J=6.1 \mathrm{~Hz}, 2 \mathrm{H}), 1.84-1.79(\mathrm{~m}, 2 \mathrm{H}), 1.78-1.73(\mathrm{~m}, 2 \mathrm{H}) .{ }^{13} \mathrm{C} \mathrm{NMR}(150 \mathrm{MHz}$, $\left.\mathrm{CDCl}_{3}\right) \delta 173.4,156.0,153.1,150.7,138.6,134.2,133.5,132.0,124.9,124.7,120.2,118.1,115.7,111.4,60.7$, 
50.9, 41.3, 39.8, 28.5, 24.3, 22.1, 20.8. ESI-MS $m / z$ 546.2 [M + H] ${ }^{+}$. HR-ESI-MS: [M + H] ${ }^{+}$calculated for $\mathrm{C}_{24} \mathrm{H}_{26} \mathrm{Br}_{2} \mathrm{~N}_{3} \mathrm{O}_{2}+546.0386$, found 546.0393 .

2-(3,5-Dibromo-4-methoxyphenyl)-N-(3-((1,2,3,4-tetrahydroacridin-9-yl)amino) propyl)acetamide (10b). White solid. Yield: $51 \mathrm{mg}, 36.4 \%$. Mp. $72.3-73.1^{\circ} \mathrm{C} .{ }^{1} \mathrm{H}$ NMR $\left(600 \mathrm{MHz}, \mathrm{CDCl}_{3}\right) \delta 7.92(\mathrm{~d}, J=8.3 \mathrm{~Hz}, 1 \mathrm{H})$, $7.88(\mathrm{~d}, J=8.4 \mathrm{~Hz}, 1 \mathrm{H}), 7.54(\mathrm{dd}, J=8.4,8.0 \mathrm{~Hz}, 1 \mathrm{H}), 7.39(\mathrm{~s}, 2 \mathrm{H}), 7.34(\mathrm{dd}, J=8.3,8.0 \mathrm{~Hz}, 1 \mathrm{H}), 6.23(\mathrm{brs}$, $1 \mathrm{H}, \mathrm{NH}), 3.78(\mathrm{~s}, 3 \mathrm{H}), 3.45(\mathrm{~s}, 2 \mathrm{H}), 3.45-3.39(\mathrm{~m}, 4 \mathrm{H}), 3.04$ (brs, $2 \mathrm{H}), 2.71$ (brs, $2 \mathrm{H}), 1.92-1.88(\mathrm{~m}, 4 \mathrm{H})$, 1.82-1.76 (m, 2H). ${ }^{13} \mathrm{C}$ NMR $\left(150 \mathrm{MHz}, \mathrm{CDCl}_{3}\right) \delta 170.5,158.5,153.5,150.7,147.1,133.5,133.5,128.6$, 128.5, 124.2, 122.6, 120.4, 118.5, 116.9, 60.7, 46.0, 42.2, 37.5, 33.9, 31.3, 25.1, 23.1, 22.8. ESI-MS $m / z 560.0$ $[\mathrm{M}+\mathrm{H}]^{+}$. HR-ESI-MS: $[\mathrm{M}+\mathrm{H}]^{+}$calculated for $\mathrm{C}_{25} \mathrm{H}_{28} \mathrm{Br}_{2} \mathrm{~N}_{3} \mathrm{O}_{2}{ }^{+} 560.0543$, found 560.0594.

2-(3,5-Dibromo-4-methoxyphenyl)-N-(4-((1,2,3,4-tetrahydroacridin-9-yl)amino)butyl)acetamide (10c). White solid. Yield: $58.2 \mathrm{mg}, 40.5 \%$. Mp. 70.3-72.1 ${ }^{\circ} \mathrm{C} .{ }^{1} \mathrm{H}$ NMR $\left(600 \mathrm{MHz}, \mathrm{CDCl}_{3}\right) \delta 8.25(\mathrm{~d}, J=8.1 \mathrm{~Hz}, 1 \mathrm{H})$, $8.24(\mathrm{~d}, J=7.9 \mathrm{~Hz}, 1 \mathrm{H}), 8.09(\mathrm{t}, J=5.5 \mathrm{~Hz}, 1 \mathrm{H}, \mathrm{NH}), 7.59(\mathrm{dd}, J=7.9,7.5 \mathrm{~Hz} 1 \mathrm{H}), 7.47(\mathrm{~s}, 2 \mathrm{H}), 7.39(\mathrm{dd}$, $J=8.1,7.5 \mathrm{~Hz}, 1 \mathrm{H}), 6.73(\mathrm{brs}, 1 \mathrm{H}, \mathrm{NH}), 3.97-3.92(\mathrm{~m}, 2 \mathrm{H}), 3.76(\mathrm{~s}, 3 \mathrm{H}), 3.58(\mathrm{~s}, 2 \mathrm{H}), 3.36-3.31(\mathrm{~m}, 2 \mathrm{H})$, $3.12(\mathrm{t}, J=6.3 \mathrm{~Hz}, 2 \mathrm{H}), 2.66(\mathrm{t}, J=6.2 \mathrm{~Hz}, 2 \mathrm{H}), 1.99-1.93(\mathrm{~m}, 2 \mathrm{H}), 1.87-1.82(\mathrm{~m}, 2 \mathrm{H}), 1.81-1.77(\mathrm{~m}, 2 \mathrm{H})$, 1.73-1.67 (m, 2H). ${ }^{13} \mathrm{C}$ NMR $\left(150 \mathrm{MHz}, \mathrm{CDCl}_{3}\right) \delta 170.8,156.0,152.8,150.8,138.7,134.9,133.5,132.4$, $125.3,124.8,120.2,117.9,115.9,111.2,60.7,47.9,41.8,38.7,28.6,27.9,26.3,24.2,22.1,20.8$. ESI-MS $m / z$ 574.0 [M + H] $]^{+}$. HR-ESI-MS: $[\mathrm{M}+\mathrm{H}]^{+}$calculated for $\mathrm{C}_{26} \mathrm{H}_{30} \mathrm{Br}_{2} \mathrm{~N}_{3} \mathrm{O}_{2}{ }^{+}$574.0699, found 574.0714.

2-(3,5-Dibromo-4-methoxyphenyl)-N-(5-((1,2,3,4-tetrahydroacridin-9-yl)amino)pentyl)acetamide (10d). White solid. Yield: $84.1 \mathrm{mg}, 57.1 \%$. Mp. 74.6-76.0 ${ }^{\circ} \mathrm{C} .{ }^{1} \mathrm{H} \mathrm{NMR}\left(600 \mathrm{MHz}, \mathrm{CDCl}_{3}\right) \delta 7.93(\mathrm{~d}, J=8.4 \mathrm{~Hz}, 1 \mathrm{H})$, $7.89(\mathrm{~d}, J=8.3 \mathrm{~Hz}, 1 \mathrm{H}), 7.54(\mathrm{dd}, J=8.3,7.1 \mathrm{~Hz}, 1 \mathrm{H}), 7.39(\mathrm{~s}, 2 \mathrm{H}), 7.34(\mathrm{dd}, J=8.4,7.1 \mathrm{~Hz}, 1 \mathrm{H}), 5.69$ (brs, $1 \mathrm{H}, \mathrm{NH}), 3.85(\mathrm{~s}, 3 \mathrm{H}), 3.45(\mathrm{t}, J=7.2 \mathrm{~Hz}, 2 \mathrm{H}), 3.40(\mathrm{~s}, 2 \mathrm{H}), 3.26-3.21(\mathrm{~m}, 2 \mathrm{H}), 3.04(\mathrm{brs}, 2 \mathrm{H}), 2.69$ (brs, $2 \mathrm{H}), 1.94-1.89(\mathrm{~m}, 4 \mathrm{H}), 1.70-1.62(\mathrm{~m}, 2 \mathrm{H}), 1.54-1.47(\mathrm{~m}, 2 \mathrm{H}), 1.41-1.34(\mathrm{~m}, 2 \mathrm{H}) .{ }^{13} \mathrm{C}$ NMR $(150 \mathrm{MHz}$, $\left.\mathrm{CDCl}_{3}\right) \delta 169.7,158.5,153.4,150.8,147.4,133.7,133.5,128.7,128.5,123.8,122.9,120.3,118.5,116.1,60.8$, 49.4, 42.2, 39.7, 34.1, 31.4, 29.5, 25.0, 24.3, 23.2, 22.9. ESI-MS $m / z 588.1[\mathrm{M}+\mathrm{H}]^{+}$. HR-ESI-MS: $[\mathrm{M}+\mathrm{H}]^{+}$ calculated for $\mathrm{C}_{27} \mathrm{H}_{32} \mathrm{Br}_{2} \mathrm{~N}_{3} \mathrm{O}_{2}{ }^{+} 588.0856$, found 588.0853.

2-(3,5-Dibromo-4-methoxyphenyl)-N-(6-((1,2,3,4-tetrahydroacridin-9-yl)amino)hexyl)acetamide (10e). White solid. Yield: $98.6 \mathrm{mg}, 65.4 \%$. Mp. 72.1-74.0 ${ }^{\circ} \mathrm{C} .{ }^{1} \mathrm{H} \mathrm{NMR}\left(600 \mathrm{MHz}, \mathrm{CDCl}_{3}\right) \delta 7.93(\mathrm{~d}, J=8.5 \mathrm{~Hz}, 1 \mathrm{H})$, $7.88(\mathrm{~d}, J=8.2 \mathrm{~Hz}, 1 \mathrm{H}), 7.54(\mathrm{dd}, J=8.2,7.0 \mathrm{~Hz}, 1 \mathrm{H}), 7.39(\mathrm{~s}, 2 \mathrm{H}), 7.33(\mathrm{dd}, J=8.5,7.0 \mathrm{~Hz}, 1 \mathrm{H}), 5.73(\mathrm{brs}$, $1 \mathrm{H}, \mathrm{NH}), 3.85(\mathrm{~s}, 3 \mathrm{H}), 3.45(\mathrm{t}, J=7.2 \mathrm{~Hz}, 2 \mathrm{H}), 3.39(\mathrm{~s}, 2 \mathrm{H}), 3.23-3.18(\mathrm{~m}, 2 \mathrm{H}), 3.04(\mathrm{brs}, 2 \mathrm{H}), 2.69$ (brs, 2H), $1.93-1.89(\mathrm{~m}, 4 \mathrm{H}), 1.65-1.59(\mathrm{~m}, 2 \mathrm{H}), 1.49-1.43(\mathrm{~m}, 2 \mathrm{H}), 1.41-1.34(\mathrm{~m}, 2 \mathrm{H}), 1.32-1.26(\mathrm{~m}, 2 \mathrm{H}) .{ }^{13} \mathrm{C}$ NMR $\left(150 \mathrm{MHz}, \mathrm{CDCl}_{3}\right) \delta 169.7,158.6,153.4,150.8,147.6,133.8,133.5,128.8,128.4,123.7,123.0,120.3$, 118.4, 116.1, 60.7, 49.4, 42.2, 39.7, 34.2, 31.8, 29.5, 26.7, 26.6, 24.9, 23.2, 22.9. ESI-MS $m / z$ 602.1 [M + H] ${ }^{+}$. HR-ESI-MS: $[\mathrm{M}+\mathrm{H}]^{+}$calculated for $\mathrm{C}_{28} \mathrm{H}_{34} \mathrm{Br}_{2} \mathrm{~N}_{3} \mathrm{O}_{2}{ }^{+}$602.1012, found 602.1018.

2-(3,5-Dibromo-4-methoxyphenyl)-N-(7-((1,2,3,4-tetrahydroacridin-9-yl)amino)heptyl)acetamide (10f). White solid. Yield: $119 \mathrm{mg}, 77.4 \%$. Mp. 54.6-56.8 ${ }^{\circ} \mathrm{C} .{ }^{1} \mathrm{H}$ NMR $\left(600 \mathrm{MHz}, \mathrm{CDCl}_{3}\right) \delta 8.34(\mathrm{~d}, J=8.6 \mathrm{~Hz}, 1 \mathrm{H})$, $8.22(\mathrm{~d}, J=8.7 \mathrm{~Hz}, 1 \mathrm{H}), 7.62(\mathrm{dd}, J=8.7,7.4 \mathrm{~Hz}, 1 \mathrm{H}), 7.44(\mathrm{~s}, 2 \mathrm{H}), 7.41(\mathrm{dd}, J=8.6,7.4 \mathrm{~Hz}, 1 \mathrm{H}), 7.21(\mathrm{brs}$, $1 \mathrm{H}, \mathrm{NH}), 3.87(\mathrm{t}, J=7.2 \mathrm{~Hz}, 2 \mathrm{H}), 3.78(\mathrm{~s}, 3 \mathrm{H}), 3.55(\mathrm{~s}, 2 \mathrm{H}), 3.23-3.20(\mathrm{~m}, 2 \mathrm{H}), 3.19(\mathrm{t}, J=6.2 \mathrm{~Hz}, 2 \mathrm{H}), 2.65$ $(\mathrm{t}, J=6.1 \mathrm{~Hz}, 2 \mathrm{H}), 1.91-1.86(\mathrm{~m}, 2 \mathrm{H}), 1.84-1.77(\mathrm{~m}, 4 \mathrm{H}), 1.50-1.45(\mathrm{~m}, 2 \mathrm{H}), 1.41-1.35(\mathrm{~m}, 2 \mathrm{H}), 1.32-1.28$ (m, 4H). ${ }^{13} \mathrm{C}$ NMR $\left(150 \mathrm{MHz}, \mathrm{CDCl}_{3}\right) \delta 170.3,155.6,152.9,151.4,139.4,134.8,133.5,132.2,125.1,124.6$, 121.0, 118.0, 116.2, 111.3, 60.7, 48.4, 41.9, 39.6, 30.7, 29.2, 28.9, 28.4, 26.4, 26.4, 24.1, 22.1, 20.9. ESI-MS $m / z 616.1[\mathrm{M}+\mathrm{H}]^{+}$. HR-ESI-MS: $[\mathrm{M}+\mathrm{H}]^{+}$calculated for $\mathrm{C}_{29} \mathrm{H}_{36} \mathrm{Br}_{2} \mathrm{~N}_{3} \mathrm{O}_{2}{ }^{+} 616.1169$, found 616.1180 .

2-(3,5-Dibromo-4-methoxyphenyl)-N-(8-((1,2,3,4-tetrahydroacridin-9-yl)amino)octyl)acetamide (10g). White solid. Yield: $80.7 \mathrm{mg}, 51.2 \%$. Mp. 60.2-61.4 ${ }^{\circ} \mathrm{C} .{ }^{1} \mathrm{H}$ NMR $\left(600 \mathrm{MHz}, \mathrm{CDCl}_{3}\right) \delta 7.96(\mathrm{~d}, J=8.4 \mathrm{~Hz}, 1 \mathrm{H})$, $7.92(\mathrm{~d}, J=8.4 \mathrm{~Hz}, 1 \mathrm{H}), 7.55(\mathrm{dd}, J=8.4,7.4 \mathrm{~Hz}, 1 \mathrm{H}), 7.42(\mathrm{~s}, 2 \mathrm{H}), 7.35(\mathrm{dd}, J=8.4,7.4 \mathrm{~Hz}, 1 \mathrm{H}), 5.59$ (brs, $1 \mathrm{H}, \mathrm{NH}), 3.86(\mathrm{~s}, 3 \mathrm{H}), 3.50(\mathrm{t}, J=7.2 \mathrm{~Hz}, 2 \mathrm{H}), 3.43(\mathrm{~s}, 2 \mathrm{H}), 3.23-3.18(\mathrm{~m}, 2 \mathrm{H}), 3.07$ (brs, $2 \mathrm{H}), 2.70$ (brs, $2 \mathrm{H}), 1.94-1.90(\mathrm{~m}, 4 \mathrm{H}), 1.68-1.62(\mathrm{~m}, 2 \mathrm{H}), 1.46-1.40(\mathrm{~m}, 2 \mathrm{H}), 1.38-1.33(\mathrm{~m}, 2 \mathrm{H}), 1.31-1.23(\mathrm{~m}, 6 \mathrm{H}) .{ }^{13} \mathrm{C}$ NMR $\left(150 \mathrm{MHz}, \mathrm{CDCl}_{3}\right) \delta 169.5,158.1,153.3,151.1,147.1,133.7,133.4,128.5,128.4,123.7,122.9,120.0$, 
118.3, 115.6, 60.6, 49.3, 42.2, 39.8, 33.8, 31.7, 29.4, 29.1, 29.0, 26.7, 26.6, 24.7, 23.0, 22.7. ESI-MS $m / z$ 630.1 $[\mathrm{M}+\mathrm{H}]^{+}$. HR-ESI-MS: $[\mathrm{M}+\mathrm{H}]^{+}$calculated for $\mathrm{C}_{30} \mathrm{H}_{38} \mathrm{Br}_{2} \mathrm{~N}_{3} \mathrm{O}_{2}{ }^{+} 630.1325$, found 630.1330.

2-(3,5-Dibromo-4-methoxyphenyl)-N-(10-((1,2,3,4-tetrahydroacridin-9-yl)amino)decyl)acetamide (10h). White solid. Yield: $72.6 \mathrm{mg}, 44.1 \%$. Mp. 74.6-76.1 ${ }^{\circ} \mathrm{C} .{ }^{1} \mathrm{H} \mathrm{NMR}\left(600 \mathrm{MHz}, \mathrm{CDCl}_{3}\right) \delta 7.96(\mathrm{~d}, J=8.4 \mathrm{~Hz}, 1 \mathrm{H})$, $7.89(\mathrm{~d}, J=8.4 \mathrm{~Hz}, 1 \mathrm{H}), 7.54(\mathrm{dd}, J=8.4,7.4 \mathrm{~Hz}, 1 \mathrm{H}), 7.40(\mathrm{~s}, 2 \mathrm{H}), 7.33(\mathrm{dd}, J=8.4,7.4 \mathrm{~Hz}, 1 \mathrm{H}), 6.01$ (brs, $1 \mathrm{H}, \mathrm{NH}), 3.84(\mathrm{~s}, 3 \mathrm{H}), 3.49(\mathrm{t}, J=7.1 \mathrm{~Hz}, 2 \mathrm{H}), 3.42(\mathrm{~s}, 2 \mathrm{H}), 3.32-3.18(\mathrm{~m}, 2 \mathrm{H}), 3.04$ (brs, $2 \mathrm{H}), 2.69$ (brs, $2 \mathrm{H}), 1.92-1.88(\mathrm{~m}, 4 \mathrm{H}), 1.66-1.60(\mathrm{~m}, 2 \mathrm{H}), 1.47-1.41(\mathrm{~m}, 2 \mathrm{H}), 1.38-1.31(\mathrm{~m}, 2 \mathrm{H}), 1.29-1.20(\mathrm{~m}, 10 \mathrm{H}) .{ }^{13} \mathrm{C}$ NMR $\left(150 \mathrm{MHz}, \mathrm{CDCl}_{3}\right) \delta 169.6,158.3,153.3,151.1,147.3,134.0,133.5,128.5,128.5,123.7,123.1,120.1$, $118.3,115.7,60.7,49.5,42.2,39.9,33.9,31.8,29.5,29.4,29.4,29.3,29.2,26.9,26.9,24.8,23.1,22.8$. ESI-MS $m / z 658.2[\mathrm{M}+\mathrm{H}]^{+}$. HR-ESI-MS: $[\mathrm{M}+\mathrm{H}]^{+}$calculated for $\mathrm{C}_{32} \mathrm{H}_{42} \mathrm{Br}_{2} \mathrm{~N}_{3} \mathrm{O}_{2}{ }^{+} 658.1638$, found 658.1637.

2-(2-Bromo-4-methoxyphenyl)-N-(7-((1,2,3,4-tetrahydroacridin-9-yl)amino)heptyl)acetamide (12a). Yellow oil. Yield: $81.4 \mathrm{mg}, 58.2 \%$ yield. ${ }^{1} \mathrm{H}$ NMR $\left(600 \mathrm{MHz}, \mathrm{CDCl}_{3}\right) \delta 8.41(\mathrm{~d}, J=8.5 \mathrm{~Hz}, 1 \mathrm{H}), 8.21(\mathrm{~d}, J=8.7 \mathrm{~Hz}$, $1 \mathrm{H}), 7.63(\mathrm{dd}, J=8.7,7.6 \mathrm{~Hz}, 1 \mathrm{H}), 7.41(\mathrm{dd}, J=8.5,7.6 \mathrm{~Hz}, 1 \mathrm{H}), 7.20(\mathrm{~d}, J=8.5 \mathrm{~Hz}, 1 \mathrm{H}), 7.05(\mathrm{~d}, J=2.6 \mathrm{~Hz}$, $1 \mathrm{H}), 6.80(\mathrm{dd}, J=8.5,2.6 \mathrm{~Hz}, 1 \mathrm{H}), 5.90(\mathrm{brs}, 1 \mathrm{H}, \mathrm{NH}), 3.87(\mathrm{t}, J=7.1 \mathrm{~Hz}, 2 \mathrm{H}), 3.75(\mathrm{~s}, 3 \mathrm{H}), 3.63(\mathrm{~s}, 2 \mathrm{H})$, $3.23(\mathrm{t}, J=6.2 \mathrm{~Hz}, 2 \mathrm{H}), 3.21-3.16(\mathrm{~m}, 2 \mathrm{H}), 2.63(\mathrm{t}, J=6.1 \mathrm{~Hz}, 2 \mathrm{H}), 1.91-1.86(\mathrm{~m}, 2 \mathrm{H}), 1.85-1.77(\mathrm{~m}$, 2H), 1.47-1.42 (m, 2H), 1.41-1.36 (m, 2H), 1.35-1.31 (m, 2H). 1.31-1.25 (m, 4H). ${ }^{13} \mathrm{C}$ NMR (150 MHz, $\left.\mathrm{CDCl}_{3}\right) \delta 170.2,159.4,155.0,151.6,139.4,132.2,129.8,127.1,125.3,125.1,124.5,121.3,118.4,116.1,114.0$, $111.1,55.7,48.4,43.1,39.5,30.9,29.8,29.4,28.6,26.5,26.5,24.0,22.1,20.9$. ESI-MS $m / z 538.2[\mathrm{M}+\mathrm{H}]^{+}$. HR-ESI-MS: $[\mathrm{M}+\mathrm{H}]^{+}$calculated for $\mathrm{C}_{29} \mathrm{H}_{37} \mathrm{BrN}_{3} \mathrm{O}_{2}{ }^{+}$538.2064, found 538.2060.

2-(4-Methoxyphenyl)-N-(7-((1,2,3,4-tetrahydroacridin-9-yl)amino)heptyl)acetamide (12b). Yellow oil. Yield: $43.4 \mathrm{mg}, 36.3 \%$. ${ }^{1} \mathrm{H}$ NMR $\left(600 \mathrm{MHz}, \mathrm{CDCl}_{3}\right) \delta 7.94(\mathrm{~d}, J=7.9 \mathrm{~Hz}, 1 \mathrm{H}), 7.89(\mathrm{~d}, J=8.4 \mathrm{~Hz}, 1 \mathrm{H}), 7.54$ $(\mathrm{dd}, J=8.4,7.0 \mathrm{~Hz}, 1 \mathrm{H}), 7.33(\mathrm{dd}, J=7.9,7.0 \mathrm{~Hz}, 1 \mathrm{H}), 7.14(\mathrm{~d}, J=8.6 \mathrm{~Hz}, 2 \mathrm{H}), 6.86(\mathrm{~d}, J=8.6 \mathrm{~Hz}, 2 \mathrm{H})$, $5.43(\mathrm{brs}, 1 \mathrm{H}, \mathrm{NH}), 3.78(\mathrm{~s}, 3 \mathrm{H}), 3.49(\mathrm{~s}, 2 \mathrm{H}), 3.45(\mathrm{t}, J=7.2 \mathrm{~Hz}, 2 \mathrm{H}), 3.18-3.14(\mathrm{~m}, 2 \mathrm{H}), 3.05(\mathrm{brs}, 2 \mathrm{H})$, 2.69 (brs, $2 \mathrm{H}), 1.93-1.88(\mathrm{~m}, 4 \mathrm{H}), 1.64-1.58(\mathrm{~m}, 2 \mathrm{H}), 1.41-1.36(\mathrm{~m}, 2 \mathrm{H}), 1.35-1.31(\mathrm{~m}, 2 \mathrm{H}), 1.30-1.25$ (m, 2H), 1.24-1.18 (m, 2H). ${ }^{13} \mathrm{C} \mathrm{NMR}\left(150 \mathrm{MHz}, \mathrm{CDCl}_{3}\right) \delta 171.4,158.9,158.5,150.9,147.5,130.6,128.8$, 128.4, 127.1, 123.7, 123.0, 120.3, 116.0, 114.5, 55.4, 49.5, 43.6, 39.6, 34.1, 31.8, 29.5, 29.0, 26.9, 26.7, 24.9, 23.1, 22.8. ESI-MS $m / z 460.2[\mathrm{M}+\mathrm{H}]^{+}$. HR-ESI-MS: $[\mathrm{M}+\mathrm{H}]^{+}$calculated for $\mathrm{C}_{29} \mathrm{H}_{38} \mathrm{~N}_{3} \mathrm{O}_{2}{ }^{+} 460.2959$, found 460.2950 .

2-(3-Bromo-4-methoxyphenyl)-N-(7-((1,2,3,4-tetrahydroacridin-9-yl)amino)heptyl)acetamide (12c). Yellow oil. Yield: $50.8 \mathrm{mg}, 36.3 \% .{ }^{1} \mathrm{H}$ NMR $\left(600 \mathrm{MHz}, \mathrm{CDCl}_{3}\right) \delta 8.49(\mathrm{~d}, J=7.4 \mathrm{~Hz}, 1 \mathrm{H}), 8.16(\mathrm{~d}, J=8.7 \mathrm{~Hz}, 1 \mathrm{H}), 7.68$ $(\mathrm{dd}, J=8.7,7.3 \mathrm{~Hz}, 1 \mathrm{H}), 7.43(\mathrm{dd}, J=7.4,7.3 \mathrm{~Hz}, 1 \mathrm{H}), 7.44(\mathrm{~d}, J=2.1 \mathrm{~Hz}, 1 \mathrm{H}), 7.18(\mathrm{dd}, J=8.4,2.1 \mathrm{~Hz}$, $1 \mathrm{H}), 6.84(\mathrm{~d}, J=8.4 \mathrm{~Hz}, 1 \mathrm{H}), 5.86(\mathrm{brs}, 1 \mathrm{H}, \mathrm{NH}), 3.87(\mathrm{brs}, 2 \mathrm{H}), 3.86(\mathrm{~s}, 3 \mathrm{H}), 3.49(\mathrm{~s}, 2 \mathrm{H}), 3.29(\mathrm{t}, J=6.2 \mathrm{~Hz}$, $2 \mathrm{H}), 3.23-3.18(\mathrm{~m}, 2 \mathrm{H}), 2.60(\mathrm{t}, J=6.0 \mathrm{~Hz}, 2 \mathrm{H}), 1.96-1.90(\mathrm{~m}, 2 \mathrm{H}), 1.90-1.84(\mathrm{~m}, 3 \mathrm{H}), 1.82-1.76(\mathrm{~m}, 2 \mathrm{H})$, $1.48-1.39(\mathrm{~m}, 4 \mathrm{H}), 1.37-1.32(\mathrm{~m}, 2 \mathrm{H}), 1.31-1.26(\mathrm{~m}, 2 \mathrm{H}) .{ }^{13} \mathrm{C} \mathrm{NMR}\left(150 \mathrm{MHz}, \mathrm{CDCl}_{3}\right) \delta 171.1,155.4$, 154.9, 151.6, 139.6, 134.0, 132.0, 129.6, 129.3, 125.1, 124.5, 121.3, 116.3, 112.1, 111.7, 111.4, 56.4, 48.4, 42.3, $39.5,30.8,29.3,29.0,28.5,26.5,26.4,24.1,22.1,20.9$. ESI-MS $m / z 538.1[\mathrm{M}+\mathrm{H}]^{+}$. HR-ESI-MS: [M + H] ${ }^{+}$ calculated for $\mathrm{C}_{29} \mathrm{H}_{37} \mathrm{BrN}_{3} \mathrm{O}_{2}{ }^{+}$538.2064, found 538.2070.

2-(2-Bromophenyl)-N-(7-((1,2,3,4-tetrahydroacridin-9-yl)amino)heptyl)acetamide (12d). Yellow oil. Yield: $90.4 \mathrm{mg}, 68.4 \% .{ }^{1} \mathrm{H}$ NMR $\left(600 \mathrm{MHz}, \mathrm{CDCl}_{3}\right) \delta 8.21(\mathrm{~d}, J=8.1 \mathrm{~Hz}, 1 \mathrm{H}), 8.07(\mathrm{~d}, J=8.5 \mathrm{~Hz}, 1 \mathrm{H}), 7.60(\mathrm{dd}$, $J=8.5,7.3 \mathrm{~Hz}, 1 \mathrm{H}), 7.54(\mathrm{dd}, J=8.0,1.0 \mathrm{~Hz}, 1 \mathrm{H}), 7.38(\mathrm{dd}, J=8.1,7.3 \mathrm{~Hz}, 1 \mathrm{H}), 7.33(\mathrm{dd}, J=7.6,1.7 \mathrm{~Hz}$, $1 \mathrm{H}), 7.28(\mathrm{ddd}, J=7.8,7.6,1.0 \mathrm{~Hz}, 1 \mathrm{H}), 7.13(\mathrm{ddd}, J=8.0,7.8,1.7 \mathrm{~Hz}, 1 \mathrm{H}), 5.67$ (brs, $1 \mathrm{H}, \mathrm{NH}), 3.69$ $(\mathrm{s}, 2 \mathrm{H}), 3.69-3.66(\mathrm{~m}, 4 \mathrm{H}), 3.23-3.18(\mathrm{~m}, 2 \mathrm{H}), 3.17(\mathrm{t}, J=6.1 \mathrm{~Hz}, 2 \mathrm{H}), 2.64(\mathrm{t}, J=6.0 \mathrm{~Hz}, 2 \mathrm{H}), 1.93-1.84$ $(\mathrm{m}, 4 \mathrm{H}), 1.75-1.68(\mathrm{~m}, 2 \mathrm{H}), 1.47-1.41(\mathrm{~m}, 2 \mathrm{H}), 1.40-1.34(\mathrm{~m}, 2 \mathrm{H}), 1.34-1.29(\mathrm{~m}, 2 \mathrm{H}), 1.29-1.25(\mathrm{~m}, 2 \mathrm{H})$. ${ }^{13} \mathrm{C}$ NMR $\left(150 \mathrm{MHz}, \mathrm{CDCl}_{3}\right) \delta 169.7,154.5,153.5,142.8,135.2,133.1,131.8,130.5,129.1,128.0,127.7$, 125.0, 124.5, 123.8, 117.9, 113.2, 48.9, 44.1, 39.6, 31.3, 31.0, 29.4, 28.7, 26.7, 26.6, 24.3, 22.5, 21.7. ESI-MS $m / z 508.1[\mathrm{M}+\mathrm{H}]^{+}$. HR-ESI-MS: $[\mathrm{M}+\mathrm{H}]^{+}$calculated for $\mathrm{C}_{28} \mathrm{H}_{35} \mathrm{BrN}_{3} \mathrm{O}^{+}$508.1958, found 508.1963.

2-(3-Bromophenyl)-N-(7-((1,2,3,4-tetrahydroacridin-9-yl)amino)heptyl)acetamide (12e). Yellow oil. Yield: $56.7 \mathrm{~m}, 42.9 \% .{ }^{1} \mathrm{H} \mathrm{NMR}\left(600 \mathrm{MHz}, \mathrm{CDCl}_{3}\right) \delta 7.94(\mathrm{~d}, J=7.8 \mathrm{~Hz}, 1 \mathrm{H}), 7.89(\mathrm{~d}, J=8.4 \mathrm{~Hz}, 1 \mathrm{H}), 7.54(\mathrm{dd}$, 
$J=8.4,7.1 \mathrm{~Hz}, 1 \mathrm{H}), 7.41-7.36(\mathrm{~m}, 2 \mathrm{H}), 7.33(\mathrm{dd}, J=7.8,7.1 \mathrm{~Hz}, 1 \mathrm{H}), 7.19-7.16(\mathrm{~m}, 2 \mathrm{H}), 5.64(\mathrm{brs}, 1 \mathrm{H}$, $\mathrm{NH}), 3.49(\mathrm{~s}, 2 \mathrm{H}), 3.46(\mathrm{t}, J=7.2 \mathrm{~Hz}, 2 \mathrm{H}), 3.20-3.15(\mathrm{~m}, 2 \mathrm{H}), 3.04$ (brs, 2H), 2.69 (brs, 2H), 1.93-1.88 $(\mathrm{m}, 4 \mathrm{H}), 1.65-1.58(\mathrm{~m}, 2 \mathrm{H}), 1.43-1.37(\mathrm{~m}, 2 \mathrm{H}), 1.37-1.30(\mathrm{~m}, 2 \mathrm{H}), 1.30-1.26(\mathrm{~m}, 2 \mathrm{H}), 1.24-1.20(\mathrm{~m}, 2 \mathrm{H})$. ${ }^{13} \mathrm{C}$ NMR $\left(150 \mathrm{MHz}, \mathrm{CDCl}_{3}\right) \delta 170.1,158.4,151.0,147.4,137.5,132.4,130.5,130.5,128.6,128.5,128.1$, 123.7, 123.0, 123.0, 120.2, 115.9, 49.5, 43.4, 39.7, 34.0, 31.7, 29.4, 29.0, 26.9, 26.7, 24.9, 23.1, 22.8. ESI-MS $m / z 508.1[\mathrm{M}+\mathrm{H}]^{+}$. HR-ESI-MS: $[\mathrm{M}+\mathrm{H}]^{+}$calculated for $\mathrm{C}_{28} \mathrm{H}_{35} \mathrm{BrN}_{3} \mathrm{O}^{+}$508.1958, found 508.1949.

2-(4-Bromophenyl)-N-(7-((1,2,3,4-tetrahydroacridin-9-yl)amino)heptyl)acetamide (12f). Yellow oil. Yield: $51.8 \mathrm{mg}, 39.2 \% .{ }^{1} \mathrm{H}$ NMR $\left(600 \mathrm{MHz}, \mathrm{CDCl}_{3}\right) \delta 7.93(\mathrm{~d}, J=8.5 \mathrm{~Hz}, 1 \mathrm{H}), 7.88(\mathrm{~d}, J=8.4 \mathrm{~Hz}, 1 \mathrm{H}), 7.53$ $(\mathrm{dd}, J=8.4,7.0 \mathrm{~Hz}, 1 \mathrm{H}), 7.43(\mathrm{~d}, J=8.3 \mathrm{~Hz}, 2 \mathrm{H}), 7.33(\mathrm{dd}, J=8.5,7.0 \mathrm{~Hz}, 1 \mathrm{H}), 7.11(\mathrm{~d}, J=8.3 \mathrm{~Hz}, 2 \mathrm{H})$, 5.57 (brs, 1H, NH), $3.47(\mathrm{~s}, 2 \mathrm{H}), 3.45(\mathrm{t}, J=7.3 \mathrm{~Hz}, 2 \mathrm{H}), 3.19-3.14(\mathrm{~m}, 2 \mathrm{H}), 3.04(\mathrm{brs}, 2 \mathrm{H}), 2.69$ (brs, $2 \mathrm{H})$, $1.93-1.87(\mathrm{~m}, 4 \mathrm{H}), 1.64-1.57(\mathrm{~m}, 2 \mathrm{H}), 1.42-1.35(\mathrm{~m}, 2 \mathrm{H}), 1.34-1.30(\mathrm{~m}, 2 \mathrm{H}), 1.29-1.25(\mathrm{~m}, 2 \mathrm{H}), 1.23-1.19$ (m, 2H). ${ }^{13} \mathrm{C}$ NMR $\left(150 \mathrm{MHz}, \mathrm{CDCl}_{3}\right) \delta 170.3,158.6,150.8,147.6,134.2,132.1,131.1,128.9,128.4,123.7$, $122.9,121.3,120.4,116.0,49.5,43.2,39.7,34.2,31.8,29.5,29.0,26.9,26.7,24.9,23.2,22.9$. ESI-MS $m / z$ $508.1[\mathrm{M}+\mathrm{H}]^{+}$. HR-ESI-MS: $[\mathrm{M}+\mathrm{H}]^{+}$calculated for $\mathrm{C}_{28} \mathrm{H}_{35} \mathrm{BrN}_{3} \mathrm{O}^{+}$508.1958, found 508.1948.

2-(2,5-Dibromophenyl)-N-(7-((1,2,3,4-tetrahydroacridin-9-yl)amino)heptyl)acetamide (12g). Yellow oil, Yield: $54.5 \mathrm{mg}, 35.7 \% .{ }^{1} \mathrm{H}$ NMR $\left(600 \mathrm{MHz}, \mathrm{CDCl}_{3}\right) \delta 7.94(\mathrm{~d}, J=8.4 \mathrm{~Hz}, 1 \mathrm{H}), 7.89(\mathrm{~d}, J=8.3 \mathrm{~Hz}, 1 \mathrm{H}), 7.54$ $(\mathrm{dd}, J=8.3,7.0 \mathrm{~Hz}, 1 \mathrm{H}), 7.49(\mathrm{~d}, J=2.4 \mathrm{~Hz}, 1 \mathrm{H}), 7.40(\mathrm{~d}, J=8.5 \mathrm{~Hz}, 1 \mathrm{H}), 7.34(\mathrm{dd}, J=8.4,7.0 \mathrm{~Hz}, 1 \mathrm{H})$, $7.26(\mathrm{dd}, J=8.5,2.4 \mathrm{~Hz}, 1 \mathrm{H}), 5.53(\mathrm{brs}, 1 \mathrm{H}, \mathrm{NH}), 3.62(\mathrm{~s}, 2 \mathrm{H}), 3.46(\mathrm{t}, J=7.2 \mathrm{~Hz}, 2 \mathrm{H}), 3.24-3.18(\mathrm{~m}$, 2H), 3.05 (brs, 2H), 2.70 (brs, 2H), 1.94-1.89 (m, 4H), 1.65-1.59 (m, 2H), 1.46-1.41 (m, 2H), 1.38-1.33 $(\mathrm{m}, 2 \mathrm{H}), 1.32-1.27(\mathrm{~m}, 2 \mathrm{H}), 1.27-1.23(\mathrm{~m}, 2 \mathrm{H}) .{ }^{13} \mathrm{C}$ NMR $\left(150 \mathrm{MHz}, \mathrm{CDCl}_{3}\right) \delta 168.7,158.6,150.9,147.6$, 137.2, 134.5, 134.4, 132.2, 128.9, 128.4, 123.7, 123.6, 123.0, 121.8, 120.3, 116.0, 49.6, 43.9, 39.8, 34.2, 31.8, 29.5, 29.0, 26.9, 26.8, 24.9, 23.2, 22.9. ESI-MS $m / z 586.0$ [M + H] $]^{+}$. HR-ESI-MS: [M + H] ${ }^{+}$calculated for $\mathrm{C}_{28} \mathrm{H}_{34} \mathrm{Br}_{2} \mathrm{~N}_{3} \mathrm{O}^{+}$586.1063, found 586.1067.

2-(3,5-Dibromophenyl)-N-(7-((1,2,3,4-tetrahydroacridin-9-yl)amino)heptyl)acetamide (12h). Yellow oil. Yield: $56.6 \mathrm{mg}, 37.1 \% .{ }^{1} \mathrm{H}$ NMR $\left(600 \mathrm{MHz}, \mathrm{CDCl}_{3}\right) \delta 7.95(\mathrm{~d}, J=8.5 \mathrm{~Hz}, 1 \mathrm{H}), 7.90(\mathrm{~d}, J=8.4 \mathrm{~Hz}, 1 \mathrm{H}), 7.57(\mathrm{t}$, $J=1.7 \mathrm{~Hz}, 1 \mathrm{H}), 7.55(\mathrm{dd}, J=8.4,7.1 \mathrm{~Hz}, 1 \mathrm{H}), 7.35(\mathrm{~d}, J=1.7 \mathrm{~Hz}, 2 \mathrm{H}), 7.34(\mathrm{dd}, J=8.5,7.1 \mathrm{~Hz}, 1 \mathrm{H}), 5.64$ (brs, $1 \mathrm{H}, \mathrm{NH}), 3.47(\mathrm{~d}, J=7.1 \mathrm{~Hz}, 2 \mathrm{H}), 3.45(\mathrm{~s}, 2 \mathrm{H}), 3.22-3.17(\mathrm{~m}, 2 \mathrm{H}), 3.05$ (brs, $2 \mathrm{H}), 2.70$ (brs, $2 \mathrm{H})$, $1.93-1.90(\mathrm{~m}, 4 \mathrm{H}), 1.65-1.60(\mathrm{~m}, 2 \mathrm{H}), 1.44-1.39(\mathrm{~m}, 2 \mathrm{H}), 1.38-1.33(\mathrm{~m}, 2 \mathrm{H}), 1.32-1.28(\mathrm{~m}, 2 \mathrm{H}), 1.27-1.24$ (m, 2H). ${ }^{13} \mathrm{C}$ NMR $\left(150 \mathrm{MHz}, \mathrm{CDCl}_{3}\right) \delta 169.4,158.5,151.0,147.5$ 139.0, 133.0, 131.2, 128.7, 128.5, 123.8, 123.3, 123.0, 120.3, 116.0, 49.5, 42.9, 39.9, 34.1, 31.8, 29.4, 29.0, 26.9, 26.8, 24.9, 23.2, 22.9. ESI-MS $\mathrm{m} / z$ $586.0[\mathrm{M}+\mathrm{H}]^{+}$. HR-ESI-MS: $[\mathrm{M}+\mathrm{H}]^{+}$calculated for $\mathrm{C}_{28} \mathrm{H}_{34} \mathrm{Br}_{2} \mathrm{~N}_{3} \mathrm{O}^{+}$586.1063, found 586.1065.

2-(3-Bromo-4-fluorophenyl)-N-(7-((1,2,3,4-tetrahydroacridin-9-yl)amino)heptyl)acetamide (12i). Yellow oil. Yield: $55.7 \mathrm{mg}, 40.7 \% .{ }^{1} \mathrm{H}$ NMR $\left(600 \mathrm{MHz}\right.$, DMSO- $\left.d_{6}\right) \delta 8.39(\mathrm{~d}, J=8.7 \mathrm{~Hz}, 1 \mathrm{H}), 8.16(\mathrm{t}, J=5.5 \mathrm{~Hz}, 1 \mathrm{H}$, $\mathrm{NH}), 7.95(\mathrm{~d}, J=8.1 \mathrm{~Hz}, 1 \mathrm{H}), 7.84(\mathrm{dd}, J=8.1,7.5 \mathrm{~Hz}, 1 \mathrm{H}), 7.78(\mathrm{brs}, 1 \mathrm{H}, \mathrm{NH}), 7.59-7.56(\mathrm{~m}, 1 \mathrm{H}), 7.55$ $(\mathrm{dd}, J=8.7,7.5 \mathrm{~Hz}, 1 \mathrm{H}), 7.28(\mathrm{brs}, 1 \mathrm{H}), 7.26(\mathrm{~d}, J=1.0 \mathrm{~Hz}, 1 \mathrm{H}), 3.85-3.79(\mathrm{~m}, 2 \mathrm{H}), 3.40(\mathrm{~s}, 2 \mathrm{H}), 3.04-2.97$ (m, 4H), 2.65 (brs, 2H), $1.85-1.79(\mathrm{~m}, 4 \mathrm{H}), 1.73-1.66(\mathrm{~m}, 2 \mathrm{H}), 1.39-1.33(\mathrm{~m}, 2 \mathrm{H}), 1.31-1.18(\mathrm{~m}, 6 \mathrm{H}) .{ }^{13} \mathrm{C}$ NMR (150 MHz, DMSO- $\left.d_{6}\right) \delta 169.3,157.8,156.2,155.6,150.6,138.0,134.8(\mathrm{~d}, J=3.57 \mathrm{~Hz}), 133.6,132.5$, $130.2(\mathrm{~d}, J=7.24 \mathrm{~Hz}), 125.0,119.2,116.3(\mathrm{~d}, J=21.93 \mathrm{~Hz}), 115.5,111.1,107.4(\mathrm{~d}, J=20.86 \mathrm{~Hz}), 47.2,40.9$, 38.5, 29.8, 28.9, 28.2, 28.0, 26.2, 26.0, 24.0, 21.5, 20.3. ESI-MS $m / z 526.1[\mathrm{M}+\mathrm{H}]^{+}$. HR-ESI-MS: $[\mathrm{M}+\mathrm{H}]^{+}$ calculated for $\mathrm{C}_{28} \mathrm{H}_{34} \mathrm{BrFN}_{3} \mathrm{O}^{+} 526.1864$, found 526.1868 .

2-(5-Bromo-2-fluorophenyl)-N-(7-((1,2,3,4-tetrahydroacridin-9-yl)amino)heptyl)acetamide (12j). Yellow oil. Yield: $47.9 \mathrm{mg}, 35.0 \% .{ }^{1} \mathrm{H} \mathrm{NMR}\left(600 \mathrm{MHz}, \mathrm{CDCl}_{3}\right) \delta 8.03-7.96(\mathrm{~m}, 2 \mathrm{H}), 7.56(\mathrm{dd}, J=8.1,7.1 \mathrm{~Hz}, 1 \mathrm{H}), 7.44$ $(\mathrm{dd}, J=6.6,2.5 \mathrm{~Hz}, 1 \mathrm{H}), 7.37-7.32(\mathrm{~m}, 2 \mathrm{H}), 6.93(\mathrm{t}, J=9.0 \mathrm{~Hz}, 1 \mathrm{H}), 5.75(\mathrm{brs}, 1 \mathrm{H}, \mathrm{NH}), 3.55(\mathrm{t}, J=7.1 \mathrm{~Hz}$, $2 \mathrm{H}), 3.51$ (s, 2H), 3.23-3.19 (m, 2H), 3.08 (brs, 2H), 2.67 (brs, 2H), 1.92-1.88 (m, 4H), 1.69-1.62 (m, 2H), $1.47-1.41(\mathrm{~m}, 2 \mathrm{H}), 1.39-1.34(\mathrm{~m}, 2 \mathrm{H}), 1.33-1.29(\mathrm{~m}, 2 \mathrm{H}), 1.29-1.26(\mathrm{~m}, 2 \mathrm{H}) .{ }^{13} \mathrm{C} \mathrm{NMR}\left(150 \mathrm{MHz}, \mathrm{CDCl}_{3}\right)$ $\delta$ 169.1, 160.9, 159.3, 151.9, 145.7, $134.4(\mathrm{~d}, J=4.03 \mathrm{~Hz}), 132.1(\mathrm{~d}, J=8.21 \mathrm{~Hz}), 129.3,127.2,124.8(\mathrm{~d}$, $J=17.42 \mathrm{~Hz}), 124.0,123.3,119.4,117.3(\mathrm{~d}, J=23.63 \mathrm{~Hz}), 117.0(\mathrm{~d}, J=3.36 \mathrm{~Hz}), 114.9,49.3,39.8,36.7,32.9$, 
31.6, 29.4, 28.9, 26.8, 26.6, 24.7, 22.9, 22.5. ESI-MS $m / z$ 526.1 [M + H] $]^{+}$. HR-ESI-MS: $[\mathrm{M}+\mathrm{H}]^{+}$calculated for $\mathrm{C}_{28} \mathrm{H}_{34} \mathrm{BrFN}_{3} \mathrm{O}^{+}$526.1864, found 526.1867.

2-(2-Bromo-5-chlorophenyl)-N-(7-((1,2,3,4-tetrahydroacridin-9-yl)amino)heptyl)acetamide (12k). Yellow oil. Yield: $70.4 \mathrm{mg}, 49.9 \% .{ }^{1} \mathrm{H} \mathrm{NMR}\left(600 \mathrm{MHz}, \mathrm{CDCl}_{3}\right) \delta 8.37(\mathrm{~d}, J=8.5 \mathrm{~Hz}, 1 \mathrm{H}), 8.23(\mathrm{~d}, J=8.7 \mathrm{~Hz}, 1 \mathrm{H}), 7.63$ $(\mathrm{dd}, J=8.7,7.6 \mathrm{~Hz}, 1 \mathrm{H}), 7.47(\mathrm{~d}, J=2.0 \mathrm{~Hz}, 1 \mathrm{H}), 7.41(\mathrm{dd}, J=8.5,7.6 \mathrm{~Hz}, 1 \mathrm{H}), 7.25(\mathrm{~d}, J=8.2 \mathrm{~Hz}, 1 \mathrm{H})$, $7.18(\mathrm{dd}, J=8.2,2.0 \mathrm{~Hz}, 1 \mathrm{H}), 6.50$ (brs, $1 \mathrm{H}, \mathrm{NH}), 3.93-3.86(\mathrm{~m}, 2 \mathrm{H}), 3.69(\mathrm{~s}, 2 \mathrm{H}), 3.25-3.17(\mathrm{~m}, 4 \mathrm{H}), 2.63$ (brs, 2H), 1.90-1.85 (m, 2H), 1.84-1.77 (m, 4H), 1.50-1.43 (m, 2H), 1.42-1.36 (m, 2H), 1.35-1.26 (m, 4H). ${ }^{13} \mathrm{C}$ NMR $\left(150 \mathrm{MHz}, \mathrm{CDCl}_{3}\right) \delta 169.5,155.8,151.0,138.9,134.2,133.7,132.4,132.4,132.4,128.0,125.3$, 125.2, 124.7, 120.7, 115.9, 111.0, 53.6, 48.4, 43.2, 39.6, 30.8, 29.3, 28.5, 28.5, 26.5, 24.0, 22.1, 20.8. ESI-MS $m / z 542.1[\mathrm{M}+\mathrm{H}]^{+}$. HR-ESI-MS: $[\mathrm{M}+\mathrm{H}]^{+}$calculated for $\mathrm{C}_{28} \mathrm{H}_{34} \mathrm{BrClN}_{3} \mathrm{O}^{+}$542.1568, found 542.1561.

2-Phenyl-N-(7-((1,2,3,4-tetrahydroacridin-9-yl)amino)heptyl)acetamide (121). Yellow oil. Yield: $52.7 \mathrm{mg}$, 47.2\%. ${ }^{1} \mathrm{H}$ NMR $\left(600 \mathrm{MHz}, \mathrm{CDCl}_{3}\right) \delta 7.93(\mathrm{~d}, J=8.5 \mathrm{~Hz}, 1 \mathrm{H}), 7.89(\mathrm{~d}, J=8.3 \mathrm{~Hz}, 1 \mathrm{H}), 7.53(\mathrm{dd}, J=8.4$, $7.0 \mathrm{~Hz}, 1 \mathrm{H}), 7.34-7.30(\mathrm{~m}, 3 \mathrm{H}), 7.26(\mathrm{dd}, J=8.5,7.0 \mathrm{~Hz}, 1 \mathrm{H}), 7.24-7.21(\mathrm{~m}, 2 \mathrm{H}), 5.48$ (brs, $1 \mathrm{H}, \mathrm{NH})$, $3.54(\mathrm{~s}, 2 \mathrm{H}), 3.44(\mathrm{t}, J=7.2 \mathrm{~Hz}, 2 \mathrm{H}), 3.19-3.14(\mathrm{~m}, 2 \mathrm{H}), 3.05(\mathrm{brs}, 2 \mathrm{H}), 2.69(\mathrm{brs}, 2 \mathrm{H}), 1.94-1.87(\mathrm{~m}, 4 \mathrm{H})$, 1.64-1.57 (m, 2H), 1.40-1.35 (m, 2H), 1.34-1.29 (m, 2H), 1.29-1.25 (m, 2H), 1.23-1.17 (m, 2H). ${ }^{13} \mathrm{C}$ NMR $\left(150 \mathrm{MHz}, \mathrm{CDCl}_{3}\right) \delta 171.0,158.6,150.8,147.6,135.1,129.5,129.1,128.8,128.3,127.4,123.7,122.9,120.3$, 116.0, 49.5, 44.0, 39.6, 34.2, 31.8, 29.5, 29.0, 26.9, 26.7, 24.9, 23.1, 22.9. ESI-MS $m / z 430.2[\mathrm{M}+\mathrm{H}]^{+}$. HR-ESI-MS: $[\mathrm{M}+\mathrm{H}]^{+}$calculated for $\mathrm{C}_{28} \mathrm{H}_{36} \mathrm{~N}_{3} \mathrm{O}^{+} 430.2853$, found 430.2847 .

\subsection{AChE/BChE Inhibitory Assay}

The AChE and BChE inhibitory activities of compounds were determined by using a slightly modified Ellman's method [30,31]. Electric eel AChE, equine serum BChE, 5,5'-dithiobis(2-nitrobenzoic acid) (DTNB), phosphate buffer solution (PBS, pH 8.0), acetylthiocholine (ATC) iodide, and butyrylthiocholine (BUC) iodide were purchased from Sigma-Aldrich (Steinheim, Germany). Tacrine was used as positive control. Enzyme solutions were prepared at $2.0 \mathrm{U} / \mathrm{mL}$ in 2-mL aliquots. The assay medium consisted of $10 \mu \mathrm{L}$ of enzyme, $40 \mu \mathrm{L}$ of PBS, $20 \mu \mathrm{L}$ of $0.01 \mathrm{M}$ DTNB, and $10 \mu \mathrm{L}$ of tested compound. Assayed solutions of tested compounds were pre-incubated with corresponding $\mathrm{ChE}$ for $5 \mathrm{~min}$. The reaction was initiated by the addition of $20 \mu \mathrm{L}$ of $0.01 \mathrm{M}$ substrate (ATC or BUC). The activity was determined by measuring the increase in absorbance at $410 \mathrm{~nm}$ at $37^{\circ} \mathrm{C}$ in 2-min intervals using Tecan Spark multimode microplate reader (Mannedorf, Switzerland). The percentage of inhibition (I) was calculated from the measured data as follows: $I=\left(\mathrm{A}_{\mathrm{c}}-\mathrm{A}_{\mathrm{i}}\right) / \mathrm{A}_{\mathrm{c}} \times 100 \%$, where $A_{i}$ and $A_{c}$ represent the change in the absorbance in the presence of an inhibitor and without an inhibitor, respectively.

\subsection{Kinetic Assay}

Kinetic studies of inhibition on AChE and BChE were performed by using Ellman's method as described above. The concentrations of used substrates were $0.07813 \mu \mathrm{M}, 0.1563 \mu \mathrm{M}, 0.3125 \mu \mathrm{M}$, and $0.625 \mu \mathrm{M}$. Linear regression was used for calculation of Lineweaver-Burk plots, and all of the calculations were performed using GraphPad Prism 5.0 software (GraphPad Software, La Jolla, CA, USA).

\subsection{Molecular Docking}

Molecular docking studies were performed using the Autodock 4.2 program (The Scripps Research Institute, La Jolla, CA, USA) [32,33]. The crystal structure of AChE (PDB ID: 5EI5) was obtained from the Protein Data Bank after eliminating the inhibitor and water molecules. The 3D structure of the ligand was built, and performed MMFF94 minimization by using ChemBio3D Ultra 12.0 (CambridgeSoft Corporation, Cambridge, MA, USA). Using Autodock Tools 1.5.6, the preparation of the receptor was made by the addition of hydrogen atoms and Gasteiger charges, and finally an assignment of atomic types as AD4 type, and then autotorsion was used to define the rotatable bonds in the ligand preparation. The resulting enzyme structure was used as an input for the Autogrid 
program. Autogrid performed pre-calculated atomic affinity grid maps for each atom type in the ligand, plus an electrostatics map and a separate de-solvation map presented in the substrate molecule. The dimensions of the box were set to $60 \times 60 \times 60$ with grid spacing of $0.375 \AA$. Rigid ligand docking was performed for the compounds. Docking calculations were carried out using the Lamarckian genetic algorithm (LGA). The proposed docking complex image was created by Pymol 1.5 (DeLano Scientific LLC, San Carlos, California, USA).

\subsection{Determination of the Inhibitory Potency on Self- $A \beta_{1-42}$ Aggregation}

In order to investigate the inhibition of compounds on $A \beta_{1-42}$ self-aggregation, a ThT-based fluorometric assay was performed [34]. 1,1,1,3,3,3-hexafluoro-2-propanol (HFIP) pre-treated A $\beta_{1-42}$ (GL Biochem Ltd., Shanghai, China) was dissolved in DMSO to make a $200 \mu \mathrm{M}$ stock solution. The stock solution was centrifuged at the speed of $13,500 \mathrm{rpm}$ for $10 \mathrm{~min}$. The above supernatant was used for experiments. The tested compounds were dissolved in DMSO at concentrations of $0.8 \mathrm{mM}$. A screening assay for the tested compounds to inhibit A aggregation was performed by measuring ThT fluorescence emission. Compounds $(2 \mu \mathrm{L})$ and $2 \mu \mathrm{L}$ of $200 \mu \mathrm{M} \mathrm{A} \beta_{1-42}$ were added into $76 \mu \mathrm{L}$ of phosphate-buffered saline (PBS at pH 7.4) in a 96-well plate. After incubation for $24 \mathrm{~h}$ at room temperature, $80 \mu \mathrm{L}$ of $5 \mu \mathrm{M}$ of ThT solution (in $50 \mathrm{mM}$ of glycine- $\mathrm{NaOH}$ at $\mathrm{pH}$ 8.5) was added to the reaction solution. Fluorescence emission was measured at $490 \mathrm{~nm}$ with an excitation wavelength of $450 \mathrm{~nm}$ on a Tecan Spark multimode microplate reader. Identical spectra were recorded by performing the independent experiments thrice. The fluorescence intensities were compared, and the $\%$ inhibition was calculated by the following equation: $100-\left[\left(\mathrm{F}_{\mathrm{i}}-\mathrm{F}_{\mathrm{b}}\right) /\left(\mathrm{F}_{\mathrm{o}}-\mathrm{F}_{\mathrm{b}}\right) \times 100\right]$, where $\mathrm{F}_{\mathrm{i}}, \mathrm{F}_{\mathrm{o}}$ and $\mathrm{F}_{\mathrm{b}}$ are the fluorescence intensities obtained for $A \beta$ aggregation in the presence of inhibitors $A \beta_{1-42}$ and ThT; in the presence of $A \beta_{1-42}$ and THT but no inhibitors; and the blanks containing ThT only.

\subsection{Determination of the Inhibitory Potency on $A \beta_{1-42}$ Aggregation Induced by $A C h E$}

The co-incubation experiment of $A \beta_{1-42}$ with $A C h E$ was performed by ThT bioassay according to a reported protocol [35]. HFIP pre-treated $A \beta_{1-42}$ (GL Biochem Ltd., shanghai, China) was dissolved in DMSO to make a $200 \mu \mathrm{M}$ stock solution. The stock solution was centrifuged at the speed of 13,500 rpm for $10 \mathrm{~min}$. The above supernatant was used for experiments. The tested compounds were dissolved in DMSO at concentrations of $10 \mathrm{mM}$, and diluted to $640 \mu \mathrm{M}$ by phosphate-buffered saline (PBS at pH 7.4). A screening assay for tested compounds to inhibit $\mathrm{A}$ aggregation was performed by measuring ThT fluorescence emission. Compounds $(2 \mu \mathrm{L})$ and $2 \mu \mathrm{L}$ of $200 \mu \mathrm{M}$ A $\beta_{1-42}$ and $20 \mu \mathrm{L}$ AchE $(2 \mu / \mathrm{mL}$, in PBS at $\mathrm{pH}$ 8.0) were added into $76 \mu \mathrm{L}$ of PBS ( $\mathrm{pH}$ 8.0) in a 96-well plate. After incubation for $24 \mathrm{~h}$ at room temperature, $100 \mu \mathrm{L}$ of $5 \mu \mathrm{M}$ ThT solution (in $50 \mathrm{mM}$ of glycine- $\mathrm{NaOH}$ at $\mathrm{pH} 8.5$ ) was added to the reaction solution. Fluorescence emission was measured at $490 \mathrm{~nm}$ with an excitation wavelength of $450 \mathrm{~nm}$ on a Tecan Spark multimode microplate reader. Identical spectra were recorded by performing the independent experiments thrice. The fluorescence intensities were compared, and the $\%$ inhibition was calculated by the following equation: $100-\left[\left(\mathrm{F}_{\mathrm{i}}-\mathrm{F}_{\mathrm{b}}\right) /\left(\mathrm{F}_{\mathrm{o}}-\mathrm{F}_{\mathrm{b}}\right) \times 100\right]$, where $\mathrm{F}_{\mathrm{i}}, \mathrm{F}_{\mathrm{o}}$ and $\mathrm{F}_{\mathrm{b}}$ are the fluorescence intensities obtained for $A \beta$ aggregation in the presence of inhibitors $A \beta_{1-42}, A C h E$, and ThT; in the presence of $A \beta_{1-42}, \mathrm{AChE}$, and ThT but no inhibitors; and the blanks containing ThT only.

\subsection{Cytotoxicity Bioassay}

The cytotoxicity of selected compounds was evaluated on HepG2 cells. Cells were inoculated into 96-well plates. After incubation for $24 \mathrm{~h}$, the cells were treated with different concentrations of tested compounds for $24 \mathrm{~h}$, and then were incubated with $10 \mu \mathrm{L}$ of 3-(4,5-dimethylthiazol-2-yl)-2,5diphenyltetrazolium bromide (MTT) at $37^{\circ} \mathrm{C}$ for $2 \mathrm{~h}$. The formazan dye product was measured by the absorbance at $490 \mathrm{~nm}$ on a Tecan Spark multimode microplate reader. 


\section{Conclusions}

In summary, pulmonarin B (1) and a series of brominated phenylacetic acid/tacrine hybrids 10a-10h and 12a-12l were synthesized and evaluated for their anti-AD potential. Compound 1 was found to be a moderate dual AChE/BChE inhibitor and also showed inhibition on self-induced and $A C h E-i n d u c e d A \beta$ aggregation, which established $\mathbf{1}$ as an interesting marine hit for further anti-AD study. Among these hybrids, the best result was obtained for compound $\mathbf{1 2} \mathbf{j}$ with $\mathrm{IC}_{50}$ of $0.182 \pm 0.006 \mu \mathrm{M}$ for $\mathrm{AChE}$ and $0.064 \pm 0.006 \mu \mathrm{M}$ for BChE. The kinetic and molecular docking studies well confirmed $\mathbf{1 2} \mathbf{j}$ as a mixed-type AChE inhibitor. Moreover, $\mathbf{1 2} \mathbf{j}$ displayed the highest inhibitory activity against self-induced and AChE-induced $A \beta$ aggregation. In addition, compound $\mathbf{1 2} \mathbf{j}$ did not show obvious hepatotoxicity in comparison with tacrine and donepezil. In the present study, the biological evaluation together with computational analyses demonstrated these newly designed brominated phenylacetic acid/tacrine hybrids as attractive lead compounds toward the discovery of multifunctional anti-AD drugs.

Supplementary Materials: The following are available online at http:/ / www.mdpi.com/1660-3397/16/9/293/s1, Supplementary materials including ${ }^{1} \mathrm{H},{ }^{13} \mathrm{C}$ NMR and HR-ESIMS spectra for compounds 1, 10a-10h and 12a-121.

Author Contributions: Chemical synthesis and bioassay, Z.-Q.C., J.Z. and J.-L.S.; Molecular docking, K.Z.; Writing-Original Draft Preparation, C.-S.J.; Writing-Review, H.Z.; Supervision, C.-S.J. and H.Z.

Funding: This research was funded by the National Natural Science Foundation of China [No. 21672082], Shandong Key Development Project [No. 2016GSF201209], the Young Taishan Scholars Program [No. tsqn20161037], Natural Science Foundation of Shandong Province [Nos. ZR2017BH038, JQ201721], and Shandong Talents Team Cultivation Plan of University Preponderant Discipline [No. 10027].

Acknowledgments: Authors are grateful to Jin-Tong Song (School of Biological Science and Technology, University of Jinan) for NMR analytical support.

Conflicts of Interest: The authors declare no conflict of interest.

\section{References}

1. Thiratmatrakul, S.; Yenjai, C.; Waiwut, P.; Vajragupta, O.; Reubroycharoen, P.; Tohda, M.; Boonyarat, C. Synthesis, biological evaluation and molecular modeling study of novel tacrine-carbazole hybrids as potential multifunctional agents for the treatment of Alzheimer's disease. Eur. J. Med. Chem. 2014, 75, 21-30. [CrossRef] [PubMed]

2. GBD 2015 Mortality and Causes of Death Collaborators. Global, regional, and national life expectancy, all-cause mortality, and cause-specific mortality for 249 causes of death, 1980-2015: A systematic analysis for the Global Burden of Disease Study 2015. Lancet 2016, 388, 1459-1544. [CrossRef]

3. Jakk, S.L.; Senthil, V.; Yasam, V.R.; Chandrasekar, M.J.N.; Vijayaraghavan, C. The Blood Brain Barrier and its Role in Alzheimer's Therapy: An Overview. Curr. Drug Targets 2018, 19, 155-169. [CrossRef] [PubMed]

4. Yu, Y.F.; Huang, Y.D.; Zhang, C.; Wu, X.N.; Zhou, Q.; Wu, D.; Wu, Y.; Luo, H.B. Discovery of Novel Pyrazolopyrimidinone Derivatives as Phosphodiesterase 9A Inhibitors Capable of Inhibiting Butyrylcholinesterase for Treatment of Alzheimer's Disease. ACS Chem. Neurosci. 2017, 8, 2522-2534. [CrossRef] [PubMed]

5. Anand, R.; Gill, K.D.; Mahdi, A.A. Therapeutics of Alzheimer's disease: Past, present and future. Neuropharmacology 2014, 76 Pt A, 27-50. [CrossRef]

6. Kumar, A.; Singh, A.; Ekavali. A review on Alzheimer's disease pathophysiology and its management: An update. Pharmacol. Rep. 2015, 67, 195-203. [CrossRef] [PubMed]

7. Greig, N.H.; Utsuki, T.; Yu, Q.; Zhu, X.; Holloway, H.W.; Perry, T.; Lee, B.; Ingram, D.K.; Lahiri, D.K. A new therapeutic target in Alzheimer's disease treatment: Attention to butyrylcholinesterase. Curr. Med. Res. Opin. 2001, 17, 159-165. [CrossRef] [PubMed]

8. AnandSingh, P.B. A review on cholinesterase inhibitors for Alzheimer's disease. Arch. Pharm. Res. 2013, $36,375-399$. 
9. Feng, B.; Li, X.P.; Xia, J.; Wu, S. Discovery of novel isoflavone derivatives as AChE/BuChE dual-targeted inhibitors: Synthesis, biological evaluation and molecular modeling. J. Enzyme Inhib. Med. Chem. 2017, 32, 968-977. [CrossRef] [PubMed]

10. Greig, N.H.; Utsuki, T.; Ingram, D.K.; Wang, Y.; Pepeu, G.; Scali, C.; Yu, Q.S.; Mamczarz, J.; Holloway, H.W.; Giordano, T.; et al. Selective butyrylcholinesterase inhibition elevates brain acetylcholine, augments learning and lowers Alzheimer beta-amyloid peptide in rodent. Proc. Natl. Acad. Sci. USA 2005, 102, 17213-17218. [CrossRef] [PubMed]

11. Jiang, C.S.; Fu, Y.; Zhang, L.; Gong, J.X.; Wang, Z.Z.; Xiao, W.; Zhang, H.Y.; Guo, Y.W. Synthesis and biological evaluation of novel marine-derived indole-based 1,2,4-oxadiazoles derivatives as multifunctional neuroprotective agents. Bioorg. Med. Chem. Lett. 2015, 25, 216-220. [CrossRef] [PubMed]

12. Zhu, J.; Yang, H.; Chen, Y.; Lin, H.; Li, Q.; Mo, J.; Bian, Y.; Pei, Y.; Sun, H. Synthesis, pharmacology and molecular docking on multifunctional tacrine-ferulic acid hybrids as cholinesterase inhibitors against Alzheimer's disease. J. Enzyme Inhib. Med. Chem. 2018, 33, 496-506. [CrossRef] [PubMed]

13. Wu, W.Y.; Dai, Y.C.; Li, N.G.; Dong, Z.X.; Gu, T.; Shi, Z.H.; Xue, X.; Tang, Y.P.; Duan, J.A. Novel multitarget-directed tacrine derivatives as potential candidates for the treatment of Alzheimer's disease. J. Enzyme Inhib. Med. Chem. 2017, 32, 572-587. [CrossRef] [PubMed]

14. Blunt, J.W.; Copp, B.R.; Keyzers, R.A.; Munro, M.H.G.; Prinsep, M.R. Marine natural products. Nat. Prod. Rep. 2014, 31, 160-258. [CrossRef] [PubMed]

15. Zhang, J.; Zhang, H.; Alexandre Muehlmann, L.; Jiang, C.S.; Guo, Y.W. Synthesis and Structural Modification of Marine Natural Products. Molecules 2017, 22, 882. [CrossRef] [PubMed]

16. Gribble, G.W. Biological Activity of Recently Discovered Halogenated Marine Natural Products. Mar. Drugs 2015, 13, 4044-4136. [CrossRef] [PubMed]

17. Sakai, R.; Swanson, G.T. Recent progress in neuroactive marine natural products. Nat. Prod. Rep. 2014, 31, 273-309. [CrossRef] [PubMed]

18. Li, J.C.; Zhang, J.; Rodrigues, M.C.; Ding, D.J.; Longo, J.P.; Azevedo, R.B.; Muehlmann, L.A.; Jiang, C.S. Synthesis and evaluation of novel 1,2,3-triazole-based acetylcholinesterase inhibitors with neuroprotective activity. Bioorg. Med. Chem. Lett. 2016, 26, 3881-3885. [CrossRef] [PubMed]

19. Zhang, J.; Jiang, C.S. Synthesis and evaluation of coumarin/piperazine hybrids as acetylcholinesterase inhibitors. Med. Chem. Res. 2018, 27, 1717-1727. [CrossRef]

20. Zhang, J.; Li, J.C.; Song, J.L.; Cheng, Z.Q.; Sun, J.Z.; Jiang, C.S. Synthesis and evaluation of coumarin/1,2,4-oxadiazoles hybrids as selective BChE inhibitors with neuroprotective activity. J. Asian Nat. Prod. Res. 2018. [CrossRef] [PubMed]

21. Tadesse, M.; Svenson, J.; Sepčić, K.; Trembleau, L.; Engqvist, M.; Andersen, J.H.; Jaspars, M.; Stensvåg, K.; Haug, T. Isolation and Synthesis of Pulmonarins A and B, Acetylcholinesterase Inhibitors from the Colonial Ascidian Synoicum pulmonaria. J. Nat. Prod. 2014, 77, 364-369. [CrossRef] [PubMed]

22. Blunt, J.W.; Carroll, A.R.; Copp, B.R.; Davis, R.A.; Keyzers, R.A.; Prinsep, M.R. Marine natural products. Nat. Prod. Rep. 2018, 35, 8-53. [CrossRef] [PubMed]

23. Jeřábek, J.; Uliassi, E.; Guidotti, L.; Korábečný, J.; Soukup, O.; Sepsova, V.; Hrabinova, M.; Kuča, K.; Bartolini, M.; Peña-Altamira, L.E.; et al. Tacrine-resveratrol fused hybrids as multi-target-directed ligands against Alzheimer's disease. Eur. J. Med. Chem. 2017, 127, 250-262. [CrossRef] [PubMed]

24. Nepovimova, E.; Korabecny, J.; Dolezal, R.; Babkova, K.; Ondrejicek, A.; Jun, D.; Sepsova, V.; Horova, A.; Hrabinova, M.; Soukup, O.; et al. Tacrine-trolox hybrids: A novel class of centrally active, nonhepatotoxic multi-target-directed ligands exerting anticholinesterase and antioxidant Activities with low in vivo toxicity. J. Med. Chem. 2015, 58, 8985-9003. [CrossRef] [PubMed]

25. Chen, Y.; Zhu, J.; Mo, J.; Yang, H.; Jiang, X.; Lin, H.; Gu, K.; Pei, Y.; Wu, L.; Tan, R.; et al. Synthesis and bioevaluation of new tacrine-cinnamic acid hybrids as cholinesterase inhibitors against Alzheimer's disease. J. Enzyme Inhib. Med. Chem. 2018, 33, 290-302. [CrossRef] [PubMed]

26. Delogu, G.L.; Matos, M.J.; Fanti, M.; Era, B.; Medda, R.; Pieroni, E.; Fais, A.; Kumar, A.; Pintus, F. 2-Phenylbenzofuran derivatives as butyrylcholinesterase inhibitors: Synthesis, biological activity and molecular modeling. Bioorg. Med. Chem. Lett. 2016, 26, 2308-2313. [CrossRef] [PubMed] 
27. Rydberg, E.H.; Brumshtein, B.; Greenblatt, H.M.; Wong, D.M.; Shaya, D.; Williams, L.D.; Carlier, P.R.; Pang, Y.P.; Silman, I.; Sussman, J.L. Complexes of alkylene-linked tacrine dimers with Torpedo californica acetylcholinesterase: Binding of bis5-tacrine produces a dramatic rearrangement in the active-site gorge. J. Med. Chem. 2006, 49, 5491-5500. [CrossRef] [PubMed]

28. Barbosa, M.; Valentão, P.; Andrade, P.B. Bioactive Compounds from Macroalgae in the New Millennium: Implications for Neurodegenerative Diseases. Mar. Drugs 2014, 12, 4934-4972. [CrossRef] [PubMed]

29. Mosmann, T. Rapid colorimetric assay for cellular growth and survival: Application to proliferation and cytotoxicity assays. J. Immunol. Methods 1983, 65, 55-63. [CrossRef]

30. Ellman, G.L.; Courtney, K.D.; Andres, V.; Feather-Stone, R.M. A new and rapid colorimetric determination of acetylcholinesterase activity. Biochem. Pharmacol. 1961, 7, 88-95. [CrossRef]

31. Talesa, T.N. Acetylcholinesterase in Alzheimer's Disease. Mech. Ageing Dev. 2001, 122, 1961-1969. [CrossRef]

32. Morris, G.M.; Goodsell, D.S.; Halliday, R.S.; Huey, R.; Hart, W.E.; Belew, R.K.; Olson, A.J. Automated Docking Using a Lamarckian Genetic Algorithm and and Empirical Binding Free Energy Function. J. Comput. Chem. 1998, 19, 1639-1662. [CrossRef]

33. Huey, R.; Morris, G.M.; Olson, A.; Goodsell, D.S. A semiempirical free energy force field with charge-based desolvation. J. Comput. Chem. 2007, 28, 1145-1152. [CrossRef] [PubMed]

34. Fang, L.; Fang, X.; Gou, S.; Lupp, A.; Lenhardt, I.; Sun, Y.; Huang, Z.; Chen, Y.; Zhang, Y.; Fleck, C. Design, synthesis and biological evaluation of D-ring opened galantamine analogs as multifunctional anti-Alzheimer agents. Eur. J. Med. Chem. 2014, 76, 376-386. [CrossRef] [PubMed]

35. Jalili-Baleh, L.; Nadri, H.; Moradi, A.; Bukhari, S.N.A.; Shakibaie, M.; Jafari, M.; Golshani, M.; Homayouni Moghadam, F.; Firoozpour, L.; Asadipour, A.; et al. New racemic annulated pyrazolo[1,2-b]phthalazines as tacrine-like AChE inhibitors with potential use in Alzheimer's disease. Eur. J. Med. Chem. 2017, 139, 280-289. [CrossRef] [PubMed]

(C) 2018 by the authors. Licensee MDPI, Basel, Switzerland. This article is an open access article distributed under the terms and conditions of the Creative Commons Attribution (CC BY) license (http:/ / creativecommons.org/licenses/by/4.0/). 